\title{
Project Work Plan
}

\section{Sequestration of Strontium-90 Subsurface \\ Contamination in the Hanford 100-N Area by Surface Infiltration of an Apatite Solution}

JE Szecsody

April 2006

Pacific Northwest National Laboratory

Operated by Battelle for the U.S. Department of Energy

Richland, Washington 99352 


\title{
DISCLAIMER
}

This report was prepared as an account of work sponsored by an agency of the United States Government. Neither the United States Government nor any agency thereof, nor Battelle Memorial Institute, nor any of their employees, makes any warranty, express or implied, or assumes any legal liability or responsibility for the accuracy, completeness, or usefulness of any information, apparatus, product, or process disclosed, or represents that its use would not infringe privately owned rights. Reference herein to any specific commercial product, process, or service by trade name, trademark, manufacturer, or otherwise does not necessarily constitute or imply its endorsement, recommendation, or favoring by the United States Government or any agency thereof, or Battelle Memorial Institute. The views and opinions of authors expressed herein do not necessarily state or reflect those of the United States Government or any agency thereof.

\author{
PACIFIC NORTHWEST NATIONAL LABORATORY \\ operated by \\ BATTELLE \\ for the \\ UNITED STATES DEPARTMENT OF ENERGY \\ under Contract DE-AC05-76RL01830
}

Printed in the United States of America
Available to DOE and DOE contractors from the Office of Scientific and Technical Information,
P.O. Box 62, Oak Ridge, TN 37831-0062;
ph: (865) 576-8401
fax: $(865)$ 576-5728
email: reports@adonis.osti.gov

\begin{abstract}
Available to the public from the National Technical Information Service, U.S. Department of Commerce, 5285 Port Royal Rd., Springfield, VA 22161 ph: (800) 553-6847 fax: $(703) 605-6900$ email: orders@ntis.fedworld.gov online ordering: http://www.ntis.gov/ordering.htm
\end{abstract}

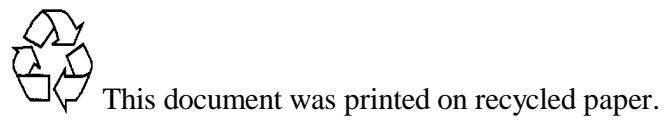




\section{Contents}

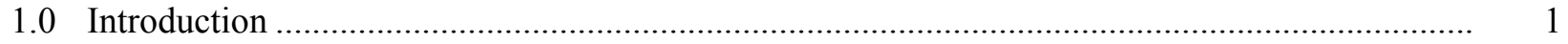

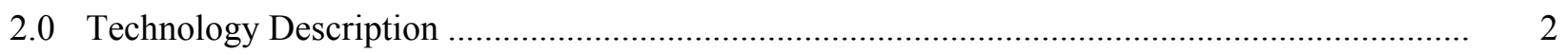

2.1 Sr-90 Contamination in Subsurface and River Biota ..................................................... 3

2.2 Sr-90 Immobilization with Apatite …........................................................................ 3

2.3 Apatite-Forming Solution Technology ......................................................................... 3

2.4 Need for Infiltration Strategy at River Shore .................................................................. 4

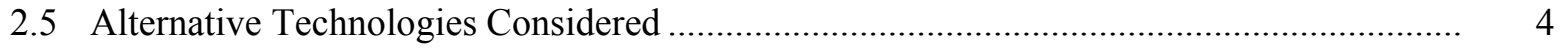

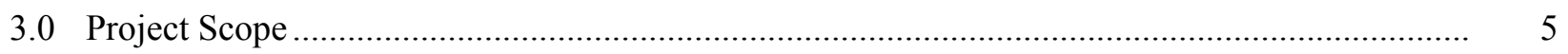

3.1 Task 1 - Apatite Formation at Low Water Saturation ..................................................... 5

3.2 Task 2 - Infiltration at Variable Ca-Citrate- $\mathrm{PO}_{4}$ Concentration ........................................... 6

3.3 Task 3 - Apatite Sr Capacity and Uptake Rate ................................................................. 7

3.4 Task 4 - Simulation of Apatite-Forming Solution Infiltration.......................................... 9

3.5 Task 5 - Apatite Spatial Distribution from Surface Infiltration ......................................... 11

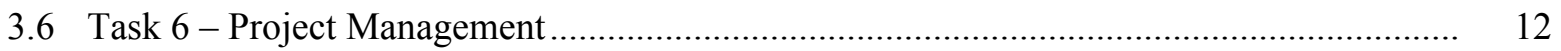

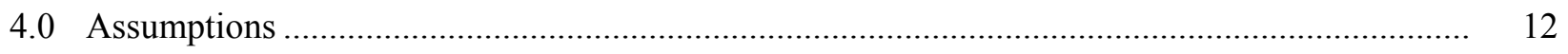

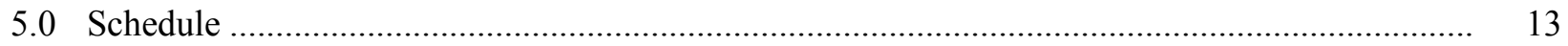

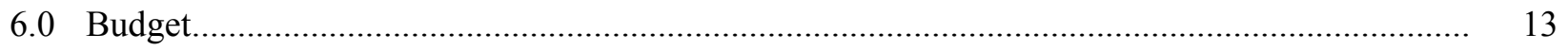

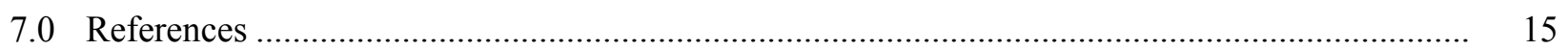

Appendix A - Scientific Basis for Proposed Laboratory Testing

Appendix B - Response to Summary Comments from Supplemental Columbia River Activities Peer Review

\section{Figures}

1 Reactions of Precipitation of Apatite from a Ca- $-\mathrm{PO}_{4}$-Citrate Solution Followed by Sr Substitution into Apatite

\section{Tables}

1 Schedule for the Apatite Infiltration Experimental Plan 


\subsection{Introduction}

Strontium-90 (Sr-90) discharge from past-practice liquid waste disposal sites in the Hanford 100-N Area have resulted in Sr-90 release to groundwater, Columbia River, and biota on the Columbia River bank. Although liquid discharges were terminated in 1993, Sr-90 adsorbed on aquifer solids remains as a continuing source to the Columbia River. Due to Sr-90 radioactive decay and adsorption, only the Sr-90 within 328 meters (100 feet) of the river bank is at risk of discharge to the river, so the inland pump-andtreat system (at a cost of $\$ 1 \mathrm{M} / \mathrm{yr}$ ) that removes Sr-90 does not reduce potential discharge to the river and, therefore, does not meet the remedial action objectives of the record of decision (ROD). A treatability test plan is in place to install a 90-meter (300-foot) apatite permeable reactive barrier (PRB) test wall near the shore in FY 2006. The proposed treatability test for the treatment technology is consistent with the requirements and remedial action objectives of the ROD for Interim Action issued in 1999 (Thompson 2005). Sr-90 sequestration by this technology occurs by injection of Ca-citrate- $\mathrm{PO}_{4}$ solution, in situ biodegradation of citrate resulting in apatite $\left[\mathrm{Ca}_{6}\left(\mathrm{PO}_{4}\right)_{10}(\mathrm{OH})_{2}\right]$ precipitation, adsorption of Sr-90 to the apatite, then apatite recrystallization with $\mathrm{Sr}-90$ substitution for $\mathrm{Ca}$ (permanent) with the natural radioactive decay of Sr-90. Laboratory-scale studies have quantified the sequential processes of this technology in 100-N Area sediment. The current implementation plan is to inject a low concentration (10 $\mathrm{mM}$ citrate) apatite-forming solution, which should result in sufficient removal capacity of Sr-90 for $\sim 10$ years followed by higher concentration injections to develop further capacity. Because most ( $50 \%$ to $70 \%$ ) of the Sr-90 contamination is in the shallow, variably saturated Hanford formation, the most efficient means of treating this zone may be surface infiltration of the apatite-forming solution, but there has been no development of this technology for vadose zone application.

We propose to develop an infiltration strategy that defines the precipitation rate of an apatite-forming solution and Sr-90 sequestration processes under variably saturated (low water content) conditions. We will develop this understanding through small-scale column studies, intermediate-scale two-dimensional (2-D) experiments, and numerical modeling to quantify individual and coupled processes associated with apatite formation and Sr-90 transport during and after infiltration of the Ca-citrate- $\mathrm{PO}_{4}$ solution.

Development of capabilities to simulate these coupled biogeochemical processes during both injection and infiltration will be used to determine the most cost-effective means to emplace an in situ apatite barrier with a longevity of 300 years to permanently sequester Sr-90 until it decays. Biogeochemical processes that will be investigated are citrate biodegradation and apatite precipitation rates at varying water contents as a function of water content. Coupled processes that will be investigated include the influence of apatite precipitation (which occupies pore space) on the hydraulic and transport properties of the porous media during infiltration.

The regulatory milestones include a proposed Tri-Party Agreement change agreement consistent with objectives of the ROD (Thompson 2005) to emplace (i.e., inject using wells) apatite in the 100-N sediments and evaluate its performance against other alternatives (i.e., infiltration of apatite solution, phytoremediation) including pump-and-treat technologies and submit a draft Comprehensive Environmental Response, Compensation, and Liability Act (CERCLA) proposed plan in March 2008. Therefore, the technology insertion point of apatite infiltration (this proposal) to develop the technology is driven by the March 2008 milestone to evaluate alternative technologies. There were three workshops open to the public (including representatives of several Indian nations) and stakeholders (U.S. Department of Energy [DOE], Washington State Department of Ecology, U.S. Environmental Protection Agency [EPA] 
participation) about this apatite technology (August 2003, August 2004, and December 2005) in which questions on application to the Hanford 100-N Area were addressed. The current plan for apatite solution injection is described in the 100-NR-02 Treatability Test Plan (DOE 2005), with a milestone of September 30, 2006, for completion of well injection. Successful completion of this project of the development of an infiltration method for the apatite solution would be implemented by Fluor Hanford, Inc. through a similar treatability test plan. DOE Richland Operations Office will be coordinating initiation of this proposed project with the Hanford Advisory Board, tribal representatives, regulatory agencies, and stakeholders.

\subsection{Technology Description}

This proposal describes use of the same apatite-forming solution (Ca-citrate-phosphate) technology proven to precipitate apatite by injection in Hanford formation sediment, but develops an infiltration strategy for emplacement in the difficult to inject Hanford formation. This infiltration strategy will supplement the current treatability test plan (DOE 2005) for well injection of the Ca-citrate- $\mathrm{PO}_{4}$ solution and is needed to reach the Tri-Party Agreement technology evaluation milestone (milestone M-016014(b); Thompson 2005) for evaluating technologies in the 100-N Area by March 2008. These alternate technologies (apatite installation by infiltration and phytoremediation) will not be sufficiently developed without proposal funding in time for this milestone. Infiltration of the solution from the land surface is advantageous for several reasons: (1) implementation can occur at a larger range of river stages compared with well injection, (2) it will treat sediments in the entire vadose zone profile so will immobilize Sr-90 in sediments that would not be reached through well injection, (3) potentially is less expensive to implement relative to well injection, and (4) sediments closer to the river can be treated due to limitations in well drilling too near the river bank. While the formation of apatite precipitation from the apatite-forming solution has been shown to occur, development of the technology was focused on water saturated (aerobic, anaerobic) processes, and experiments have not been conducted at low water saturation.

We will develop an understanding of the apatite-forming solution infiltration processes for the purpose of designing an efficient infiltration strategy. The combined effects of biogeochemical and coupled precipitate/flow processes will be quantified so that an infiltration strategy that produces a relatively uniform spatial distribution of the apatite precipitate can be achieved at the field scale. We propose a sequence of experiments that increase in complexity and scale to quantify individual and coupled processes of apatite precipitation during liquid infiltration and Sr-90 sequestration. Small-scale experiments will investigate citrate biodegradation rates as a function of water content and microbial population (Task 1). Low water content infiltration experiments will also be conducted at differing apatite-forming solution concentrations (Task 2). High solution concentration injections add complexities to both the infiltration method and initial Sr-90 migration, as previously shown in water-saturated systems. Theoretically, precipitation of $1.3 \mathrm{mg}$ of apatite per gram of sediment should remove all $\mathrm{Sr}$ and Sr-90 for 300 years (10 half-lives of Sr-90), assuming 11\% Sr substitution for Ca (found in natural apatites). Whether the theoretical capacity can be achieved in the 100-N Area depends on the rate at which $\mathrm{Sr}-90$ is incorporated into the apatite structure relative to the Sr-90 flux rate. We will conduct long-term apatite recrystallization rate experiments to address the rate at which $\mathrm{Sr}$ is incorporated into apatite (Task 3). Processes quantified in these small-scale experiments will be incorporated into the 
STOMP simulator to determine the relative importance of processes, design larger scale experiments, and develop both injection and infiltration strategies (Task 4). This simulation tool will also be used to design 2-D infiltration experiments (Task 5) that will be conducted to experimentally investigate the coupled effects of apatite-forming solution infiltration, alteration of hydraulic and transport properties due to mineral precipitation, biofilm formation, and $\mathrm{CO}_{2}$ evolution, and the effects of these coupled processes on the final spatial distribution of apatite.

\subsection{Sr-90 Contamination in Subsurface and River Biota}

The operation of the Hanford 100-N Area nuclear reactor required the disposal of pass-through cooling water from the reactor's primary cooling loop, the spent fuel storage basins, and other reactorrelated sources. Liquid discharges to two disposal trenches/cribs contained radioactive fission and activation products, including cobalt-60, cesium-137, strontium-90 and tritium. Sr-90 transport in subsurface sediments from disposal cribs has reached the Columbia River, as evidenced by Sr-90 in the river, in river biota (clams, see Appendix A for details) and in the sediments in groundwater. The proposed 300-ft wide treatment zone of apatite will cover a zone up and downstream of the highest Sr-90 contamination.

\subsection{Sr-90 Immobilization with Apatite}

Apatite $\left[\mathrm{Ca}_{10}\left(\mathrm{PO}_{4}\right)_{6}(\mathrm{OH})_{2}\right]$ is a natural calcium phosphate mineral occurring primarily in the earth's crust as phosphate rock. Apatite minerals are very stable and practically insoluble in water (Wright 1990; Wright et al. 2004). The solubility product of hydroxyapatite is about $10^{-44}$, while quartz crystal, which is considered the most stable mineral in the weathering environment, has a solubility product $\left(\mathrm{K}_{\mathrm{sp}}\right)$ of $10^{-4}$ (Geochem. Software 1994). Strontiapatite, $\mathrm{Sr}_{10}\left(\mathrm{PO}_{4}\right)_{6}(\mathrm{OH})_{2}$, which is formed by the complete substitution of $\mathrm{Ca}$ by $\mathrm{Sr}$ (or $\mathrm{Sr}-90$ ), has a $\mathrm{K}_{\mathrm{sp}}$ of about $10^{-51}$, another $10^{7}$ times less soluble than hydroxyapatite (Verbeek et al. 1977). The substitution of strontium for calcium in the crystal structure is thermodynamically favorable, and will proceed provided the two elements coexist. Sr substitution in natural apatites is as high as $11 \%$, although dependent on available $\mathrm{Sr}$ (Belousova et al. 2002). Synthetic apatites have been made with up to $40 \% \mathrm{Sr}$ substitution for $\mathrm{Ca}$ (Heslop et al. 2005). The feasibility of Sr-90 sequestration by aqueous injection of apatite has been demonstrated at the bench-scale at Sandia National Laboratories (Moore et al. 2004, 2005) and at Pacific Northwest National Laboratory using a series of batch tests that investigated in situ apatite precipitation and ${ }^{90} \mathrm{Sr}$ sorption/immobilization. Longterm (1 year+) laboratory studies have shown that the Sr-90 initially adsorbs to sediments, then is slowly incorporated into the apatite structure (data shown in Figure A.4, Appendix A).

\subsection{Apatite-Forming Solution Technology}

The method of emplacing apatite in subsurface sediments at the 100-N Area is to inject an aqueous solution containing a Ca-citrate complex and Na-phosphate. Relatively slow biodegradation of the Ca-citrate complex (days) allows sufficient time for injection and transport of the reagents to the areas of the aquifer where treatment is required. As Ca-citrate is degraded, the free $\mathrm{Ca}$ and phosphate combine to form amorphous apatite. The formation of amorphous apatite occurs within a week and crystalline apatite forms within a few weeks. Citrate is biodegraded in Hanford 100-N Area sediments (water-saturated) in days (Appendix A). 


\subsection{Need for Infiltration Strategy at River Shore}

The current plan (baseline) to inject the apatite-forming solution separately into the Hanford formation and Ringold E Formation sediments through a series of wells. While there is a high degree of confidence that apatite precipitate will occur, the river hydrodynamics create a significant problem for the seasonal timing of the injection. Apatite-forming solution injection into the upper Hanford formation needs to be done during high river stage so that the formation is water saturated (i.e., late spring). In addition, because movement of the apatite-forming solution is desired toward the river, the most desirable injection river stage would be a high river stage (saturating the formation) followed by a moderate river stage, to get slow flow toward the river. Injection during low river stage would result in rapid movement of the injection solution into the river (days) before precipitation would occur. Therefore, river hydrodynamics have a potentially significant influence on the effectiveness of the emplacement of the apatite-forming solution by injection. There are only short periods throughout the year where the river stage conditions are optimal for injection.

Infiltration of the apatite-forming solution (proposed, described in the following sections) could be accomplished at a different river stage than injection, so an infiltration strategy extends the amount of time that apatite could be emplaced. Infiltration into the Hanford formation sediments would be optimal at periods of low river stage (leaving a greater thickness of unsaturated porous media), so could occur during summer/fall, or the second low stage of early spring. The formation of apatite during infiltration during these periods is less influenced by transmissivity in the formation and river stage, and more dependent on the rate of infiltration. Another potential benefit to infiltration is that cost of implementation may be much less than injection, as wells (a significant cost) do not need to be installed, although there is some cost associated with the infiltration method (i.e., trenches, drip emitters, etc).

\subsection{Alternative Technologies Considered}

Some of the Sr-90 mitigation alternatives are described in the treatability test plan for the groundwater injection (DOE 2005). Alternatives for treatment were evaluated and described in a 2001 document (Hanford 100N Area Remediation Options Evaluation Summary Report). Monitored natural attenuation (i.e., radioactive decay of Sr-90) will remove considerable Sr-90 mass from much of the plume, but not the portion near the river shore, which is entering the river. Soil flushing, clinoptilolite, sheet pile, cryogenic barrier were all evaluated and some attempted (soil flushing, sheet pile). In 2004, Fluor/CH2M HILL reevaluated alternative technologies and reiterated the conclusion of the 2001 ITRD report that phytoremediation and apatite (in some form) are the most promising. Evaluated for effectiveness, implementability, reduction of near-shore contamination, public acceptance, risk, and cost, several apatite technologies were considered acceptable: aqueous injection, air injection (solid apatite), hydrofracture, and hydrofracture grout curtain. Air injection of solid apatite was not viable due to the near surface need (i.e., insufficient overburden of sediment to force apatite laterally into formation). Hydrofracturing might work, although has not been attempted using apatite. This alternative was considered too expensive, and in addition, there was no evaluation as to the effectiveness of a very thin (2-4 inch) apatite barrier having sufficient residence time to sequester all the $\mathrm{Sr} / \mathrm{Sr}-90$ from groundwater. 
Weaknesses of the proposed apatite infiltration technology include: a) some disturbance of the near shore surface (infiltration emitters), and b) Sr-90 is left in place until it decays. Sr-90 decays at 3.6\% per year (50\% remaining after 30 years, $10 \%$ after 100 years, $0.1 \%$ after 300 years, planned barrier lifetime), so $\mathrm{Sr}-90$ is not permanently left in place.

\subsection{Project Scope}

The following work elements describe the sequence of experiments that increase in complexity and scale to quantify individual and coupled processes of apatite infiltration. Small-scale experiments will investigate citrate biodegradation rates as a function of water content and microbial population (Task 1). Low water content one-dimensional (1-D) infiltration experiments will be conducted at differing apatiteforming solution concentrations (Task 2). The rate and extent to which Sr-90 is incorporated into apatite will be determined in long-term studies (Task 3). Processes quantified in these experiments will be incorporated into a numerical code to determine the relative importance of processes, design larger scale experiments, and develop the infiltration strategy (Task 4). Finally, the infiltration strategy will be tested in a 2-D experimental system for homogeneous (Task 5.1) and layered (Task 5.2) sediments. Project management is described in Task 6 . The technical basis for the amount of apatite and 300-year longevity are described in Task 3.

\subsection{Task 1 - Apatite Formation at Low Water Saturation}

In this task, the influence of water saturation on citrate biodegradation (Task 1.1) and apatite formation (Task 1.2) will be investigated. While water-saturated experiments have demonstrated that apatite precipitate will form after citrate biodegradation in Hanford sediments, we have no supporting data at low water saturation.

Hypothesis. Because citrate is biodegraded more rapidly in oxic environments than anaerobic environments, we hypothesize that for sediments with high water saturation $(50 \%$ to $<100 \%)$ will biodegrade more rapidly than water-saturated sediments, but sediments at low water saturation $10 \%$ to $50 \%$ will show low citrate biodegradation rates due to mass transfer limitations.

Go/No-Go Decision. Citrate biodegradation occurs at low water saturation conditions that will be used during infiltration $(50-100 \%$ saturation) $($ no $=$ stop work, $6 / 07)$

The citrate biodegradation rate can be assessed by measurements of aqueous citrate, calcium, and phosphate concentrations (reactants) or products carbon dioxide (oxic system) or organic acids acetate and formate (anaerobic system). Measurement of aqueous species at low water saturation is problematic, so citrate biodegradation rates will be assessed by measurements of carbon dioxide formation using $14^{\circ} \mathrm{C}$ labeled citrate. These gas-phase samplers cause minimal disturbance to experiments at differing water saturations. For these batch experiments, water saturations of $100 \%, 90 \%, 80 \%, 60 \%, 40 \%$, and $20 \%$ will be used. It should be noted that in preliminary infiltration simulations, water saturations of $60 \%$ or greater were generally observed in the apatite-forming solution infiltration area, so it is expected that higher water saturations are more applicable to field scale infiltration. These citrate biodegradation rate experiments will be assessed at $15^{\circ} \mathrm{C}$ and $25^{\circ} \mathrm{C}$ to be able to predict biodegradation rates that should be 
observed over the small temperature range expected in the field $\left(14^{\circ} \mathrm{C}\right.$ to $17^{\circ} \mathrm{C}$, and possibly as high as $21^{\circ} \mathrm{C}$ in late summer for near-shore sediments). In these batch experiments, $0.25 \mathrm{~mL}$ tubes containing $1 \mathrm{M}$ $\mathrm{NaOH}$ will be used as carbon dioxide traps. These traps will be periodically sampled and refilled over time (to $1,000 \mathrm{~h}$ ) to measure the rate of carbon dioxide production from the $14^{\circ} \mathrm{C}$ citrate biodegradation. The $14^{\circ} \mathrm{C}$ carbon dioxide will be measured by liquid scintillation counting.

The formation of apatite will be confirmed by elemental analysis on a transmission electron microprobe (TEM) from thin sections of the sediment/precipitate encased in epoxy. This type of analysis is currently in progress and is being combined with autoradiography to measure the amount of Sr-90 radiation. Ultimately, the Sr-90 will be compared spatial to the apatite distribution to show how much of the $\mathrm{Sr}-90$ is associated with apatite.

Finally, the influence of the microbial biomass on the citrate biodegradation rate will be investigated (Task 1.3). The microbial population profile with depth has been measured in three boreholes in the $100-\mathrm{N}$ Area, which shows the population varying 2 orders of magnitude in the Hanford formation $\left(10^{5}\right.$ to $10^{7} \mathrm{CFU} / \mathrm{g}$ ), with even greater variation in the Ringold Formation. It is hypothesized that the citrate biodegradation rate will be somewhat slower with a lower microbial biomass, but not directly related to the relative biomass (i.e., 10x lower biomass will not result in 10x slower citrate biodegradation). Lower initial biomass will require somewhat longer lag time to grow the biomass necessary to degrade the citrate. Batch experiments will be conducted with sediments over a range of biomass to assess the citrate biodegradation rate under unsaturated conditions by measurement of the $14^{\circ} \mathrm{C}$-carbon dioxide production rate, as described earlier.

\subsection{Task 2 - Infiltration at Variable Ca-Citrate- $\mathrm{PO}_{4}$ Concentration}

In this task, a series of 1-D unsaturated column experiments will be conducted to assess rates at which apatite precipitation occurs during 1-D transport with varying Ca-citrate- $\mathrm{PO}_{4}$ concentration.

Hypothesis. Uniform apatite precipitate distribution can be achieved at low solution concentration, and low infiltration rates, but microbial growth at high solution concentrations will create spatially different apatite precipitate zones.

Go/No-Go Decision. Apatite will form during 1-D infiltration in 100-N Area sediments that is relatively uniform $($ no $=$ stop work, $8 / 07)$.

In the water-saturated zone during injection, high concentration (100 $\mathrm{mM}$ citrate) apatite solutions are $3 \%-4 \%$ more dense than groundwater, so density effects (plume sinking) may be significant. In the unsaturated zone, density effects should be less significant due to the mitigating effects of capillarity. These studies move up in scale to idealized 1-D representation of field infiltration (beyond the batch studies in Task 1).

In this task, 1-D infiltration experiments will be conducted at differing apatite solution concentrations ranging from $10 \mathrm{mM}$ to $100 \mathrm{mM}$ citrate. These 1-D unsaturated column studies will be conducted in conjunction with 1-D simulations conducted in Task 4 to design experiments and assess results. In Subtask 2.1, column transport experiments will be conducted at a fixed infiltration rate (steady flow), with measurement of $\mathrm{Ca}, \mathrm{PO}_{4}$, and citrate aqueous concentrations and the moisture content. The aqueous samples will be collected through small porous ceramic lysimeters ( $1 \mathrm{~mm}$ diameter by $3 \mathrm{~mm}$ length) 
placed in the 1-2 meter long column. Moisture content and pressure head will be measured nonintrusively at selected points in space and time over the column length using an automated dual-energy gamma radiation measurement system and/or time domain reflectrometry (TDR), and tensiometers with pressure transducers, respectively. In Subtask 2.2, the infiltration rate and duration will be varied. Based on preliminary 2-D simulations of infiltration in Hanford formation, high infiltration rates result in nearly water-saturated conditions in the sediment vertical profile, whereas very low infiltration rates result in 60\%-70\% water saturation and slower transport rates in the sediment profile. Interestingly, these simulated infiltration studies showed that the additional residence time during slow infiltration resulted in sufficient time for citrate biodegradation, so there was a relatively uniform apatite distribution predicted. These results need to be confirmed experimentally, first in 1-D columns, then in 2-D studies (Task 5).

In Subtask 2.3, the influence of heterogeneities will be investigated in 1-D columns including a high$\mathrm{K}$ zone and a low-K zone in the center of the column. To fully address the flow field that will develop as a result of heterogeneities, 2-D experiments will be conducted (Task 5), but some necessary information (i.e., influence of precipitation on hydraulic properties) is gained from these 1-D experiments with heterogeneities that are used to aid in the design of the 2-D experiments. Because the Hanford formation (and underlying Ringold E Formation) is fluvial deposits, thin units of either coarser material (higher energy deposits) or silts do occur, and if identified, an infiltration strategy can be modified to some extent to address the influence of these heterogeneities. Hydraulic properties (capillary pressure-saturationpermeability relations) of the Hanford formation sediments will be determined from independent experiments.

\subsection{Task 3 - Apatite Sr Capacity and Uptake Rate}

In this task, the uptake of Sr-90 into apatite will be characterized to determine: a) total mass of apatite precipitate needed to sequester $\mathrm{Sr}-90$ for $\sim 300$ years (sufficient time for radioactive decay given the Sr-90 half-life of 29.1 years), and b) rate of Sr-90 uptake into the apatite structure.

Hypothesis. Only a small amount of apatite is needed to sequester Sr-90 for 300 years, but that the rate at which apatite recrystallizes and incorporates $\mathrm{Sr} / \mathrm{Sr}-90$ will define the amount of apatite mass needed to be emplaced by infiltration.

Go/No-Go Decision. Sr is uptaken at a rate sufficiently rapid to exceed the Sr-90 average flux rate in water-saturated sediments $(9 / 07$, no $=$ stop work). If the $\mathrm{Sr}$ capacity is $<1 \%$ in apatite, it would be difficult to inject enough apatite to sequester Sr-90 for 300 years as the amount of apatite would fill most of the pore space $(1 / 08)$.

In Subtask 3.1, the capacity of apatite to uptake $\mathrm{Sr} / \mathrm{Sr}-90$ will be determined experimentally. As described in the background section, some natural apatites have up to $11 \%$ substitution of $\mathrm{Sr}$ for $\mathrm{Ca}$. Given this $11 \%$ substitution, a total of $1.7 \mathrm{mg}$ of apatite per gram of sediment is needed to sequester $\mathrm{Sr}$ and $\mathrm{Sr}-90$ for 300 years. Given that the initial apatite precipitate is somewhat amorphous, and relatively pure Ca-apatite $\left[\mathrm{Ca}_{10}\left(\mathrm{PO}_{4}\right)_{6}(\mathrm{OH})_{2}\right]$, the substitution approaching $11 \% \mathrm{Sr}\left[\mathrm{SrCa}_{9}\left(\mathrm{PO}_{4}\right)_{6}(\mathrm{OH})_{2}\right]$ is thermodynamically favored given the higher solubility product of strontiapatite of $10^{-51}$ being 7 orders of magnitude less soluble than apatite $\left(10^{-44}\right)$. The maximum amount of $\mathrm{Sr}$ substitution into Ca-apatite will be verified experimentally with a long-term batch study with solid phase apatite (only, no sediment) and a solution containing the proportions of cations found in Hanford $100 \mathrm{~N}$ groundwater (i.e., $\mathrm{Ca} / \mathrm{Sr}$ ratio of 220/1) to demonstrate that $\mathrm{Sr}$ substitution under these conditions will occur. 
In Subtask 3.2, the rate of $\mathrm{Sr}$ substitution into Ca-apatite will be experimentally determined through a series of long-term batch studies at different temperature $\left(22^{\circ} \mathrm{C}, 42^{\circ} \mathrm{C}, 62^{\circ} \mathrm{C}\right.$, and $\left.82^{\circ} \mathrm{C}\right)$ to be able to project the rate of $\mathrm{Sr}$ substitution that will occur under field conditions at $15^{\circ} \mathrm{C}$ and determine the activation energy of the process. Low activation energies $(<10 \mathrm{~kJ} / \mathrm{mol})$ would indicate the process is rate limited by diffusion, which could be increased by increasing the surface area (i.e., change the precipitation process to precipitate smaller crystals). Activation energies $>15 \mathrm{~kJ} / \mathrm{mol}$ would be indicative of a chemically controlled process. In these experiments, solid phase apatite, and mixtures of sediment and apatite will be used, with solid phase sampling at period time intervals to 1 year with sequential extractions to determine the amount of Sr-90 substitution into the apatite. An example of the sequential extractions that will be used show dissolution of apatite by the $4 \mathrm{M}$ nitric acid extraction with increasing Sr substitution over months.

Technical basis for apatite mass and 300-year longevity to sequester Sr-90.

1. Three hundred years of capacity is purely a function of the Sr-90 half-life (28.1 years), so $10+$ halflives would decay $99.90 \%$ of the Sr-90. Whether Sr-90 is held in the apatite or is inland from the Columbia River and does not reach the river, only $10 \%$ will remain after 100 years and $<0.1 \%$ after 300 years.

2. Basis for number of pore volumes of water passing through the barrier for 300 years: $\mathrm{pv} / 15 \mathrm{~m}$ thick barrier x $0.3 \mathrm{~m} /$ day (average gw flow) x 365.25 day/yr x $300 \mathrm{yr}=2,191 \mathrm{pv}$

or roughly 2,200 pore volumes of water traveling at $0.3 \mathrm{~m} /$ day $(1 \mathrm{ft} /$ day) average groundwater flow rate will pass through a $15 \mathrm{~m}(45-\mathrm{ft})$ thick barrier in 300 years. We need to capture all of the $\mathrm{Sr}$ and Sr-90 in these 3,000 pore volumes. Ideally, we are only interested in the Sr-90, but the solid phase substitution is the same for $\mathrm{Sr}$ and $\mathrm{Sr}-90$.

3. $\mathrm{Sr}$ advection through the barrier in 300 years $/ 2,200$ pore volumes: $0.2 \mathrm{mg} \mathrm{Sr} / \mathrm{L}$ (ave gw) or $2.0 \mathrm{E}-4$ $\mathrm{mg} \mathrm{Sr} / \mathrm{cm}^{3}$ x 2,200 pore volumes $=0.44 \mathrm{mg} \mathrm{Sr} / \mathrm{cm}^{3}$ liquid

4. Amount of apatite needed to sequester this amount of Sr: $0.44 \mathrm{mg} \mathrm{Sr} / \mathrm{cm}^{3} \times 1 /[44 \mathrm{~g} \mathrm{Sr} / 1,004 \mathrm{~g}$ apatite $(11 \%$ substitution of $\mathrm{Sr}$ for $\mathrm{Ca})]=10.01 \mathrm{mg}$ apatite $/ \mathrm{cm}^{3}$ liquid

5. Given the sediment field porosity $\left(0.20 \mathrm{~cm}^{3} / \mathrm{cm}^{3}\right)$ and dry bulk density $\left(1.78 \mathrm{~g} / \mathrm{cm}^{3}\right)$, the amount of apatite per gram of sediment is: $10.01 \mathrm{mg}$ apatite $/ \mathrm{cm}^{3}$ liquid $\mathrm{x} 0.2 \mathrm{~cm}^{3}$ liquid $/ \mathrm{cm}^{3}$ total $\mathrm{x} \mathrm{cm}^{3}$ total $/ 1.78 \mathrm{~g}$ sediment $=1.12 \mathrm{mg}$ apatite $/ \mathrm{g}$ sediment

6. Phosphate solution ( $\mathrm{mol} / \mathrm{L}$ ) required to achieve $1.2 \mathrm{mg}$ apatite/g sediment deposition mass: $10.01 \mathrm{mg}$ apatite $/ \mathrm{cm}^{3}$ liquid $\times 1,000 \mathrm{~cm}^{3} / \mathrm{L} \mathrm{x} \mathrm{g/1,000} \mathrm{mg} \mathrm{x}$ mol apatite $/ 1,004 \mathrm{~g}$ apatite $\times 6 \mathrm{~mol}$ $\mathrm{PO}_{4} / \mathrm{mol}$ apatite $=0.059 \mathrm{~mol} \mathrm{PO}_{4} /$ liter

Because phosphate solution concentrations of $0.04 \mathrm{~mol} / \mathrm{L}$ is soluble and has been used, it is estimated that two or more injections are required to achieve a deposition of $1.2 \mathrm{mg}$ apatite/g sediment

7. Volume considerations of apatite in the pore space unit cell of apatite: $\mathrm{a}=9.3 \mathrm{~A} \mathrm{x} \mathrm{c}=6.89 \mathrm{~A}$. Assume cylinder $(\mathrm{a} / 2) 2 * 3.14 * \mathrm{c}=7.488 \mathrm{x}$ $10-21 \mathrm{~cm}^{3} /$ atom or $4,509.6 \mathrm{~cm}^{3}$ per mol of apatite $1.7 \mathrm{mg}$ apatite/g sed $*$ mol/502 $\mathrm{g} * 1 / 1,000 *$ $4,509.6 \mathrm{~cm}^{3} / \mathrm{mol}=0.0153 \mathrm{~cm}^{3} / \mathrm{g}$ sed 
Give the dry bulk density and porosity: $1.78 \mathrm{~g} / \mathrm{cm}^{3} / 0.2=8.9 \mathrm{~g} / \mathrm{cm}^{3}$ pore space pore space occupied by apatite: $0.0153 \mathrm{~cm}^{3} \mathrm{ap} / \mathrm{g}$ sed $\mathrm{x} 8.9 \mathrm{~g} \mathrm{sed} / \mathrm{cm}^{3}$ pore space $=0.136$ ...or $1.7 \mathrm{mg}$ apatite/g sediment occupies $14 \%$ of the pore space (small, but likely some decrease in permeability).

8. The above pore volume calculation (b) is appropriate for groundwater flow (not vadose zone flow). Given the average annual precipitation at Hanford of $16 \mathrm{~cm} /$ year, the recharge rate (i.e., downward flux rate) is estimated at $0.1 \%$ to $2 \%$ (less with plant cover, more with coarse surface sediment and no plants), based on multiple different techniques and studies at Hanford. Therefore, downward migration of Sr-90 in the vadose zone is very slow, so technically the number of pore volumes migrating downward in the vadose zone is very small $(\sim 0.01$ pore volume/year $=1 \%$ recharge $)$, so the mass of apatite needed to sequester Sr-90 for 300 years (a) may be less.

However, the Sr-90 contamination zone that is being remediated is near the Columbia River, and this zone may be at low water saturation or be seasonally part of the unconfined aquifer. As such, the "worst case" for vadose zone treatment is that Sr-90 is migrating in groundwater (i.e., the vadose zone is watersaturated $100 \%$ of the time), so we are designing the same amount of precipitation in the vadose zone as in the saturated zone.

\subsection{Task 4 - Simulation of Apatite-Forming Solution Infiltration}

In this task, the reactions controlling apatite-forming solution injection, citrate biodegradation, apatite precipitation, $\mathrm{Sr} / \mathrm{Ca} / \mathrm{Na} / \mathrm{Mg}$ ion exchange, and $\mathrm{Sr}-90$ slow incorporation into apatite structure (Figure 1) will be incorporated into the STOMP simulator (Task 4.1). Model parameters will be calibrated using data from batch studies (Task 1 and 3) and 1-D infiltration column studies (Task 2). The model will then be used to assist in the design of 2-D experiments that will determine the accuracy of the conceptual approach for emplacement of an apatite barrier by infiltration (Task 4.2). Finally, the model will be used to design the field-scale infiltration strategy (Task 4.3).

Hypothesis. Infiltration of the Ca-citrate/phosphate solution into Hanford sediments is subject to the dynamic effects of ion exchange and biodegradation/precipitation reactions which affect the spatial distribution of $\mathrm{Ca}$ and phosphate and the resulting spatial distribution of apatite precipitate.

The current reactive transport code (STOMP) incorporates a simplified set of apatite reactions, which was used for preliminary infiltration simulations. These reactions are:

- citrate biodegradation modeled as a first-order reaction (realistic, based on sat. laboratory data)

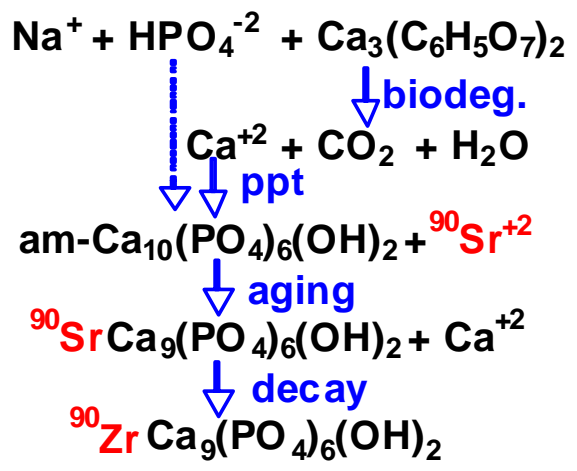

Figure 1. Reactions of Precipitation of Apatite from a $\mathrm{Ca}-\mathrm{PO}_{4}$-Citrate Solution Followed by Sr Substitution into Apatite

- rapid apatite precipitation (realistic)

- rapid, linear adsorption of phosphate (not realistic, evidence for kinetic (slow) adsorption; adsorption of this anion is $\mathrm{pH}$-dependent 
- rapid, linear adsorption of $\mathrm{Ca}^{2+}$ (not realistic, laboratory data shows that $\mathrm{Ca}^{2+}$ attachment to surfaces is controlled by ion exchange, so the exchange between $\mathrm{Ca}, \mathrm{Na}, \mathrm{Mg}$, and $\mathrm{Sr}$ during injection needs to be considered).

Task 4.1 will be to incorporate necessary reactions into the transport code. A new reactive transport module, ECKECHEM (White and McGrail 2005), has recently been written for the STOMP simulator (White and Oostrom 2004). This module solves coupled equilibrium, component, and kinetic equations for chemical reactions. However, this module does not currently account for multicomponent ionexchange processes. Task 4.1 will incorporate an ion-exchange model into STOMP, as ion-exchange reactions will have a significant influence on the injection scheme. Ion-exchange reactions are important in this remediation strategy because: a) apatite precipitation depends on the stoichiometry of $\mathrm{Ca}$ and $\mathrm{PO}_{4}$ available in the pore fluid and b) Sr-90 desorption occurs as a result of the injection of a higher ionic strength. The apparent Sr-90 $\mathrm{K}_{\mathrm{d}}$ decreases from $35 \mathrm{~cm}^{3} / \mathrm{g}$ in groundwater to 2.5 with a high ionic strength solution. To lessen the Sr-90 release into solution caused by high ionic strength addition (i.e., the salt effect), infiltrations can be staged, with an initial injection of lower solution concentrations, which would also provide for more rapid citrate biodegradation (and ultimately better control of the apatite placement). With a $40 \mathrm{mM}$ citrate injection, the $\mathrm{Sr} \mathrm{K}_{\mathrm{d}}=13 \mathrm{~cm}^{3} / \mathrm{g}$, which results in a 2x increase in Sr-90 groundwater concentration. It is hypothesized that there would be less $\mathrm{Sr}$ desorption than predicted from these studies for actual Sr-90 laden sediments that have been in contact with Sr-90 for decades (as opposed to the 5-day adsorption in this study). After several weeks of Sr-90 sequestration by the small amount of apatite, a high concentration solution can be injected.

Task 4.2 will develop a reaction network for the coupled equilibrium, component, and kinetic reactions that are expected. The complete set of reactions will include ion exchange reactions, noted above, as well as equilibrium aqueous complexation reactions associated with the variable chemistries of the groundwater, river water, and solution injection and infiltration. Most of the required laboratory experiments have been completed to characterize the binary exchange isotherms, so the work proposed in this task primarily involves parameter estimation and incorporating the appropriate form of ion exchange in the transport model.

Designing the field-scale injection strategy (Task 4.3) will be accomplished with a combination of experimental data (batch, 1-D, and 2-D) and simulations. While experimental data shows the combined effects of reactions in a specific flow field, these experimental systems are smaller in scale and typically do not incorporate natural heterogeneities found at the field scale. Simulations can be used to test the influence of a wide range of different infiltration parameters that could not all be tested experimentally. In addition, the influence of heterogeneities (randomly generated hydraulic conductivity field, for example) can be simulated to determine how significant heterogeneities are on infiltration.

An idealized set of Sr-90 reactions were used in preliminary infiltration experiments to demonstrate the influence of: a) proper reactions, and b) physical and geochemical heterogeneities. These simulations show that the level of geochemical reaction complexity and heterogeneity complexity change the timing and concentration of ${ }^{90} \mathrm{Sr}$ leaching from the system. Using a constant $\mathrm{K}_{\mathrm{d}}$ approach and homogeneous sediment (Simulation \#1), ${ }^{90} \mathrm{Sr}$ starts initially leaching at low concentration (i.e., ${ }^{90} \mathrm{Sr}$ is present in sediment near the 10-m depth), but the ${ }^{90} \mathrm{Sr}$ concentration does not change when the pulse of $\mathrm{Na}^{+}$arrives at $50 \mathrm{~h}$. All of the ${ }^{90} \mathrm{Sr}$ slowly reaches the $10-\mathrm{m}$ depth after $540 \mathrm{~h}$. Considering ion exchange and adsorption reactions of $\mathrm{Sr}^{2+}$ and $\mathrm{Na}^{+}$and both ${ }^{90} \mathrm{Sr}$ and $\mathrm{Na}^{+}$transport in homogeneous sediment (Case \#2), ${ }^{90} \mathrm{Sr}$ remains highly adsorbed to sediment until the arrival of the $\mathrm{Na}^{+}$pulse at $50 \mathrm{~h}$, when it is quickly 
forced back into solution. The peak concentration is $20 \times$ greater than a $\mathrm{K}_{\mathrm{d}}$ approach, and the ${ }^{90} \mathrm{Sr}$ mass (on average) moves $5 \times$ faster. The difference between Cases \#1 and \#2 represent the ability to incorporate changing geochemical conditions (i.e., $\mathrm{Na}^{+}$concentration in this example) into altering ${ }^{90} \mathrm{Sr}$ mobility. The peaking breakthrough curves of Sr-90 (ion exchange "snow plow" effect) do occur, as shown experimentally where injection of a higher ionic strength solution desorbs the Sr-90.

A 2-D experimental system will be used (Task 5) to test specific cases of heterogeneities on the infiltration/precipitation of apatite at a $1.5 \mathrm{~m}$ scale in $2-\mathrm{D}$, which is somewhat more realistic flow field than the batch or 1-D columns used in previous tasks.

\subsection{Task 5 - Apatite Spatial Distribution from Surface Infiltration}

In this task, the infiltration strategy for achieving a relatively uniform apatite precipitate will be experimentally tested during 2-D infiltration at a $1.5 \mathrm{~m}$ scale.

Hypothesis. Residence time is the key factor that determines how uniform the apatite precipitate distribution that can be achieved from a Ca-citrate/phosphate infiltration.

Go/No-Go Decision on Implementation. A 2-D infiltration experiment can be conducted and a relatively uniform (vertically and laterally) apatite precipitation distribution obtained (no = no go, 12/07 in time for 3/08 Tri-Party Agreement milestone).

The first 2-D infiltration experiment will be infiltration into a homogenous sediment (Task 5.1), and the second infiltration experiment will be infiltration into layered sediment (high-K zone, Task 5.2). Additional heterogeneities will be tested through simulations (Task 4) that include laterally discontinuous layers (high-K, low-K) and random zones of hydraulic conductivity of different scales. In general, batch and 1-D infiltration experiments should be sufficient for predicting solution infiltration and apatite precipitation distribution behavior in homogeneous systems. The influence of the solution density (at high concentration) is pronounced during injection in a well, but should have little effect during infiltration, as the infiltration timing is largely controlled by capillary suction in the sediment. In addition, we expect there to be little effect of the amount of apatite precipitation on the flow field. In theory, the calculated maximum amount of apatite precipitate $(1.7 \mathrm{mg} / \mathrm{g}$ of sediment $)$ to achieve 300 years of capacity would occupy $15 \%$ of the pore space. This reduction in hydraulic conductivity where precipitate forms initially would, in theory, alter the flow field for subsequent fluid to regions of higher permeability. The net effect should be a more lateral spread of the infiltration profile with the hypothesized reduction in permeability directly beneath the infiltration location. However, we expect that this effect will be insignificant, especially compared with the influence of field scale heterogeneities.

We expect that low-K and high-K heterogeneities will influence the distribution of apatite precipitate that will occur, and that in some cases, modification of the injection strategy (injection rate, variable solution concentration) can minimize these effects. A high-K layer located at depth will result in the buildup of the Ca-citrate- $\mathrm{PO}_{4}$ solution in finer grained sediments above the high-K layer, which will provide additional residence time to biodegrade the citrate and form apatite in this finer grained porous media (and less apatite precipitate in the high-K unit). If a significant high-K lens/layer is characterized at the field scale, apatite precipitate can be formed in the high-K layer by an injection of high concentration solution at a rapid infiltration rate. The water entry pressure of the high-K unit would be 
exceeded, so the solution would infiltrate the high-K unit. Because the residual saturation is lower in the high-K unit, residual saturation of a higher concentration solution will provide sufficient precipitate to form.

The residence time of the Ca-citrate- $\mathrm{PO}_{4}$ solution (to provide sufficient time for apatite precipitate to form after biodegradation) is the key to understanding the effect of a low-K unit on the solution infiltration. Vertical infiltration of the solution reaching a depth of a low-K unit will typically result in greater lateral spread of the solution in the low-K unit. There will be some resistance to water entry into the higher-K porous media under the low-K unit, so as a result, there will be a wider distribution of apatite in the low-K unit.

For the purpose of forming a precipitate barrier for Sr-90 sequestration, both unsaturated and watersaturated flow scenarios need to be considered in the Hanford formation. If the Hanford formation were to always be a vadose zone, then infiltration of the Ca-citrate- $\mathrm{PO}_{4}$ solution into the heterogeneous porous media would, in general, result in greater apatite precipitate mass in finer grained porous media. Precipitation events driving Sr-90 held in the soil profile deeper would move more readily in this finer grained porous media, so the Sr-90 would be sequestered. However, at periods of high river stage, the lower portion of the Hanford formation will be water saturated and groundwater will flow more rapidly in the higher-K portions of the sediment, which contain the least amount of apatite. Therefore, we will focus our experiments on determining the infiltration strategy to create additional precipitate in high-K zones.

Experiments in this task will be conducted in a large 2-D system that is $1.5 \mathrm{~m}$ (lateral) by $0.8 \mathrm{~m}$ (vertical) by $5 \mathrm{~cm}$ (thick), which can be scanned by a dual-source gamma system to quantify changes in moisture content.. The $\mathrm{Ca}$, citrate, and phosphate concentrations will be measured by collecting aqueous samples through small lysimeters.

\subsection{Task 6 - Project Management}

Project Support. Plan, organize, and provide top-level guidance and direction for overall project performance. Also provide project-level cost and schedule control, tracking, and reporting. Coordinate the Columbia River Protection Supplemental Technologies Project work scope with DOE, Richland Operations, the Groundwater Remediation and Closure Assessment Project, and the Office of River Protection, including participation in planning, peer reviews, and periodic project meetings.

\subsection{Assumptions}

The following assumptions pertain to this scope of work:

- The project will start on or before May 15, 2006.

- A project specific Quality Assurance Plan (QAP) is required. This will describe the type of experiments, chemical and microbial analysis, and the associated detection limits, duplicates, blind duplicates, and other quality assurance information. 
- Procurement of 100-N Area Hanford sediments will be conducted by the site remediation contractor, Fluor Hanford, Inc. Most of these sediments have already been collected from current 100-N Area drilling operations.

- This treatability study will focus on strontium sequestration in the vadose zone and will not address emplacement or performance issues associated with treatment in water-saturated porous media (currently being investigated).

- The schedule shown in this proposal will be approved by DOE and the appropriate regulatory agencies.

\subsection{Schedule}

A detailed schedule for the tasks associated with developing the apatite solution infiltration strategy is provided in Table 1.

\subsection{Budget}

The total budget for this plan is estimated to be approximately $\$ 790,000$. 
Table 1. Schedule for the Apatite Infiltration Experimental Plan

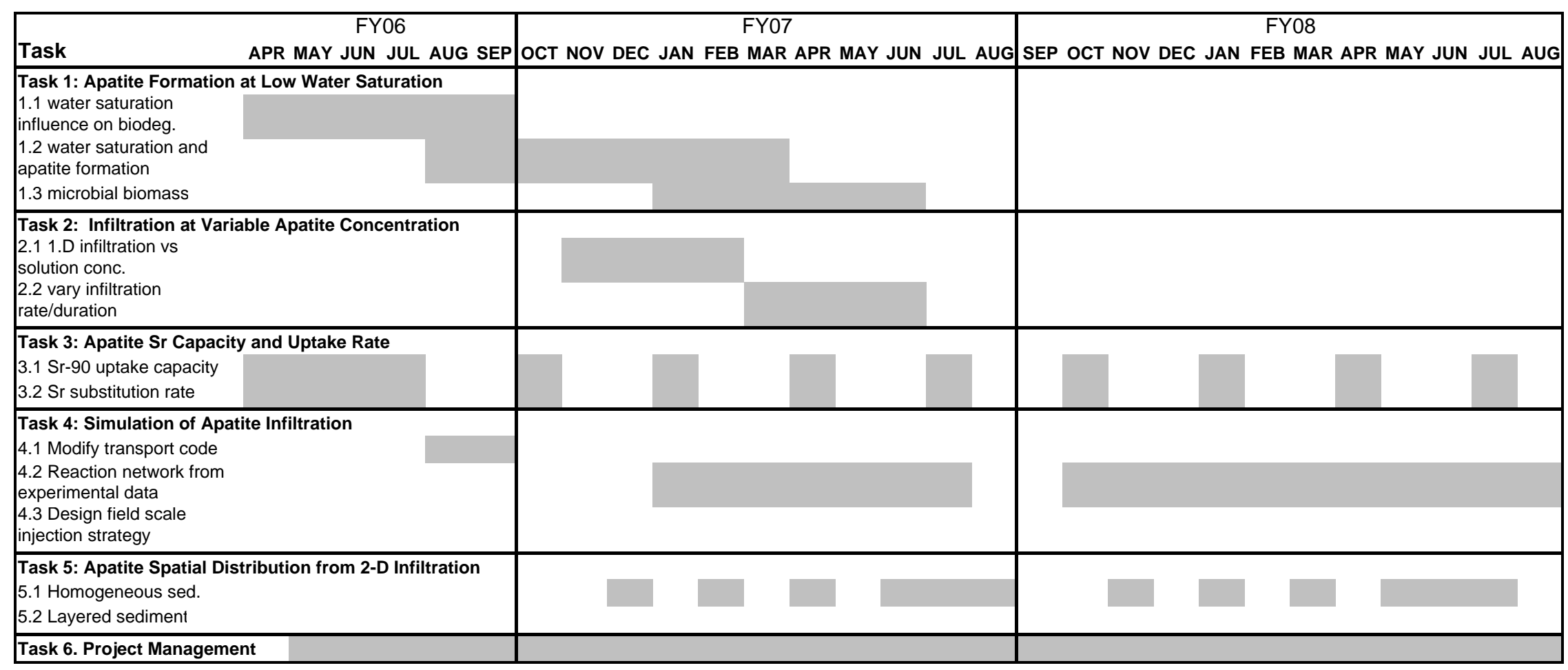




\subsection{References}

Comprehensive Environmental Response, Compensation, and Liability Act. 1980. Public Law 96-150, as amended, 94 Stat. 2767, 42 USC 9601 et seq.

DOE. 2005. Strontium-90 Treatability Test Plan for 100-NR-2 Groundwater Operable Unit.

DOE/RL-2005-96, Draft A, U.S. Department of Energy, Richland, Washington.

Heslop D, Y Bi, A Baig, M Otsuka, and W. Higuchi. 2005. "A Comparative Study of the Metastable Equilibrium Solubility Behavior of Carbonated Apatites Using $\mathrm{pH}$ and Solution Strontium as Independent Variables." J. Coll. Interf. Sci 289:14-25.

Moore RC, C Sanchez, K Holt, P Zhang, H Xu and G Choppin. 2004. "Formation of Hydroxyapatite in Soils Using Calcium Citrate and Sodium Phosphate for Control of Strontium Migration." Radiochimica Acta 92.9-11:719-723.

Moore RC, M Gasser, N Awwad, K Holt, F Salas, A Hasan, M Hasan, H Zhao, and C. Sanchez. 2005. "Sorption of Plutonium(VI) by Hydroxyapatite." J. Radioanaly. and Nuc. Chem. 263.1:97-101.

Thompson KM. 2005. Federal Facility Agreement and Consent Order Change Control Form (Tri-Party Agreement), Change Number M-16-06-01, U.S. Department of Energy, Richland, Washington.

Verbeek RM, HP Hauben, E Thun, and F. Verbeek. 1977. "Solubility and Solution Behavior of Strontium Hydroxyapatite.” Z. Phys. Chem (Wiesbaden) 108(2):203-215.

White MD and M Oostrom. 2004. STOMP Subsurface Transport Over Multiple Phases Version 3.1 User's Guide. PNNL-14478, Pacific Northwest National Laboratory, Richland, Washington.

White MD and BP McGrail. 2005. STOMP Subsurface Transport Over Multiple Phases, Version 1.0, Addendum: ECKEChem Equilibrium-Conservation-Kinetic Equation Chemistry and Reactive Transport. PNNL-15482, Pacific Northwest National Laboratory, Richland, Washington.

Wright J. 1990. "Conodont Apatite: Structure and Geochemistry." In Biomineralization: Patterns, Processes and Evolutionary Trends, J Carter (ed.), p 445-459, Van Nostrand Reinhold, New York.

Wright J, K Rice, B Murphy, and J Conca. 2004. "PIMS Using Apatite II: How It Works to Remediate Soil and Water." In Sustainable Range Management, R Hinchee and B Alleman (eds.), Battelle Press, Columbus, Ohio. 


\section{Appendix A}

\section{Scientific Basis for Proposed Laboratory Testing}




\section{Appendix A}

\section{Scientific Basis for Proposed Laboratory Testing}

\section{A.1 Sr-90 Contamination in Subsurface and River Biota}

The Hanford Site is a U.S. Department of Energy (DOE) site located in southeastern Washington State near Richland, Washington. The Hanford 100 Area is located along the Columbia River and includes nine DOE nuclear reactors previously used for plutonium production, one of which is the $100-\mathrm{N}$ Reactor. The operation of the 100-N Area nuclear reactor required the disposal of pass-through cooling water from the reactor's primary cooling loop, the spent fuel storage basins, and other reactor-related sources. Two crib and trench liquid waste disposal facilities (LWDFs) were constructed to receive these waste streams, and disposal consisted of percolation into the soil. The first LWDF (1301-N) was constructed in 1963, about 244 meters (800 feet) from the river. Liquid discharges to this facility contained radioactive fission and activation products, including cobalt-60, cesium-137, strontium-90 and tritium. Minor amounts of hazardous wastes such as sodium dichromate, phosphoric acid, lead, and cadmium were also part of the waste stream. When Sr-90 was detected at the shoreline, disposal at the first LWDF was terminated and a second crib and trench (1325-N LWDF) was constructed further inland in 1983. Discharges to $1325-\mathrm{N}$ ceased in 1993. A more complete history of the groundwater contamination at 100-N Area can be found in the Hanford 100-N Area Remediation Options Evaluation Summary Report (ITRD 2001).

Sr-90 transport in subsurface sediments from disposal cribs has reached the Columbia River, as evidenced by $\mathrm{Sr}-90$ in the river, and in the sediments in shallow water (groundwater discharges to the river, red squares, Figure A.1). In addition, Sr-90 is detected in Asian clams found on the $100-\mathrm{N}$ shoreline (circles, Figure A.1). The highest sediment and clam Sr-90 concentration is at river tube \#5. A proposed 300-ft wide treatment zone of apatite proposed will cover extend between river tubes 1 to 8 .

The sediments (gravel with sand/silt) in the 100-N Area consist of a lower Ringold E unit and overlying Hanford formation (15-20 ft

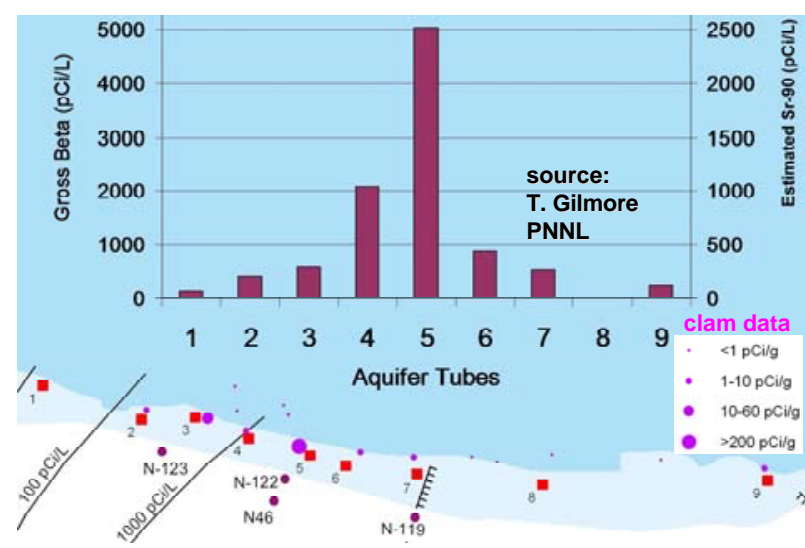

Figure A.1. Sr-90 Contamination in Sediments under River (aquifer tubes, red squares) and in Clams (circles) contact depth), which contain the unconfined aquifer. The Hanford formation is highly transmissive (Ksat $490-20,000 \mathrm{ft} /$ day) compared to the underlying Ringold E (20 - $590 \mathrm{ft} /$ day). The Ringold E unit is bounded by the underlying silty Ringold upper mud, approximately $200 \mathrm{ft}$ thick, which acts as an aquitard. Groundwater flows primarily in a north-northwesterly direction most of the year and discharges to the Columbia River. The groundwater gradient varies from 0.0005 to $0.003 \mathrm{ft} / \mathrm{ft}$. Near the LWDF facilities, average groundwater velocities are estimated to be between 0.1 and $2 \mathrm{ft} / \mathrm{d}$, with $1 \mathrm{ft} / \mathrm{d}$ average. 
Sr-90 contamination in sediments reflects the hydrodynamics in the 100-N Area. Sr-90 has leached from trenches through the variable thickness vadose zone to groundwater and moved toward the Columbia River. Because the river stage changes daily ( $\pm 5 \mathrm{ft}$ ) and seasonally ( $\pm 8 \mathrm{ft}$ for sustained periods), the saturated zone thickness changes and flow reversals do occur (i.e., movement of river water into the aquifer). The result on Sr-90 is a smearing of the plume vertically. Given that the upper Hanford formation has generally 10x greater groundwater flow than the underlying Ringold E Formation, most (but not all) of the Sr-90 contamination is found in the Hanford formation, with roughly a third of the mass in the lower Ringold E (Figure A.2). The highest
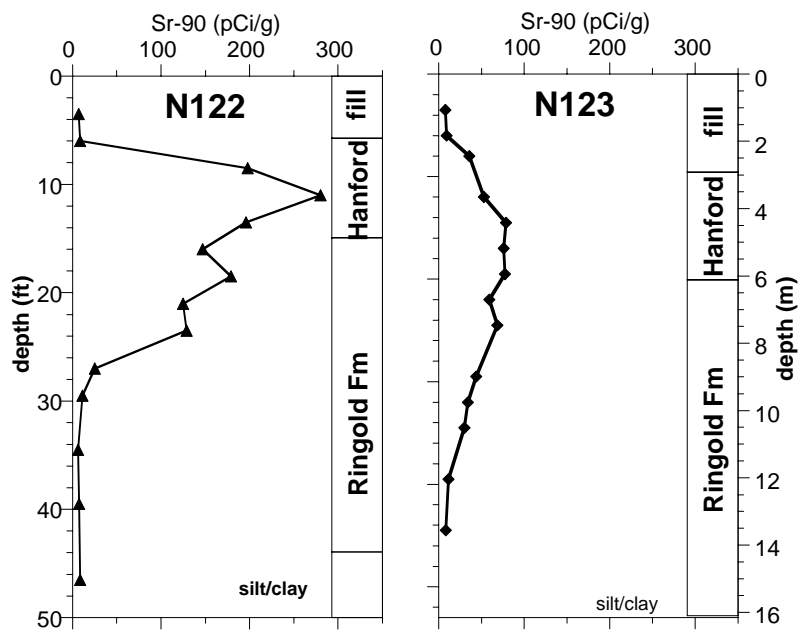

Figure A.2. Sr-90 Contamination in Subsurface Sediments concentration found $50 \mathrm{ft}$ inland from the river edge (well N-122) is inland from river tube \#5 (Figure A.1), with lower Sr-90 concentrations in wells on both sides of this location. This vertical Sr-90 profile type is previously observed (Serne and LeGore 1996).

Because of strong Sr-90 adsorption by ion exchange to sediments $\left(\mathrm{Kd}=25 \mathrm{~cm}^{3} / \mathrm{g}\right.$, Moore et al. 2006; Routson et al. 1981; Steefel 2004), about $1 \%$ of the $\mathrm{Sr}-90$ is in groundwater and $99 \%$ on sediments. As such, the pump-andtreat system operated since 1995 has only removed a small amount of Sr-90 from the aquifer, although is effective for removal of mobile contaminants such as tritium. Because of the highly transmissive nature of sediments near the river, the pump-and-treat system removes Sr-90 from inland locations near the disposal trench. Given the high adsorption and short radioactive decay half-life of Sr-90

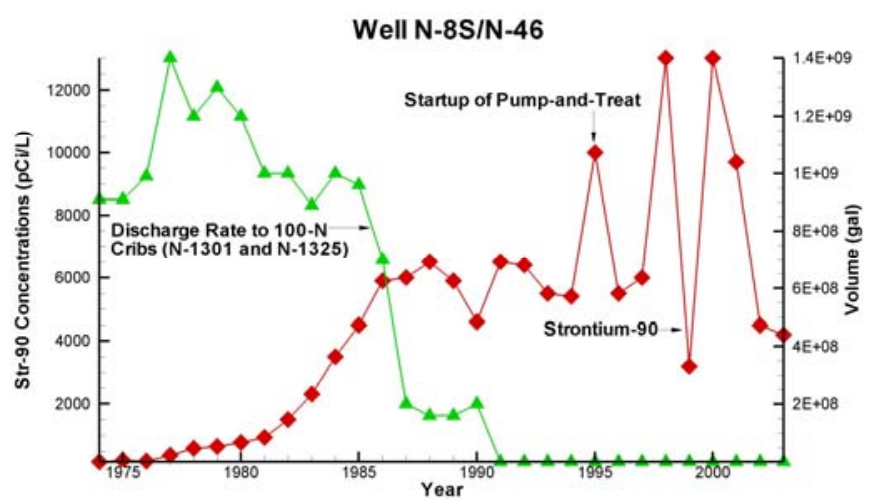

Figure A.3. Crib Discharge (green) and Sr-90 Levels in Well N-46 (29.1 years), only sediments near the river are at risk of entering the river (red/yellow highlighted area, Figure A.1) before radioactive decay reduces Sr-90 activity to negligible amounts. The pump-and-treat system has not influenced Sr-90 levels in wells near the river (red line, Figure A.3, well N-46 inland of river tube 5 and well N-122, Figure A.1).

\section{A.2 Sr-90 Immobilization with Apatite}

Apatite $\left[\mathrm{Ca}_{10}\left(\mathrm{PO}_{4}\right)_{6}(\mathrm{OH})_{2}\right]$ is a natural calcium phosphate mineral occurring primarily in the earth's crust as phosphate rock. It is also a primary component in the teeth and bones of animals. Apatite minerals sequester elements into their molecular structures via isomorphic substitution, whereby elements of similar physical and chemical characteristics replace calcium, phosphate, or hydroxide in the 
hexagonal crystal structure (Hughes et al. 1989; Spence and Shi 2005). Apatite has been used for remediation of other metals including U (Arey et al. 1999; Fuller et al. 2002, 2003; Jeanjean et al. 1995), lead (Bailliez et al. 2004; Mavropoulos et al. 2002), Pu (Moore et al. 2005), Np (Moore et al. 2003). Sr incorporation into apatite has also been previously studied (Smiciklas et al. 2005; Rendon-Angeles et al. 2000). Apatite minerals are very stable and practically insoluble in water (Tofe 1998; Wright, 1990; Wright et al. 2004). The solubility product of hydroxyapatite is about $10^{-44}$, while quartz crystal, which is considered the most stable mineral in the weathering environment, has a solubility product $\left(\mathrm{K}_{\mathrm{sp}}\right)$ of $10^{-4}$ (Geochem. Software 1994). Strontiapatite, $\mathrm{Sr}_{10}\left(\mathrm{PO}_{4}\right)_{6}(\mathrm{OH})_{2}$, which is formed by the complete substitution of $\mathrm{Ca}$ by $\mathrm{Sr}$ (or $\mathrm{Sr}-90$ ), has a $\mathrm{K}_{\mathrm{sp}}$ of about $10^{-51}$, another $10^{7}$ times less soluble than hydroxyapatite (Verbeek et al. 1977). The substitution of strontium for calcium in the crystal structure is thermodynamically favorable, and will proceed provided the two elements coexist. Sr substitution in natural apatites are as high as $11 \%$, although dependent on available $\mathrm{Sr}$ (Belousova et al. 2002). Synthetic apatites have been made with up to $40 \% \mathrm{Sr}$ substitution for $\mathrm{Ca}$ (Heslop et al. 2005).

The rate of metal incorporation into the apatite crystal lattice can be relatively slow, on the order of days to years (LeGeros 1979, 1991; Vukovic et al. 1998; Moore et al. 2003, 2005). However, in the presence of soluble phosphates, apatite acts as a seed crystal for the precipitation of metal phosphates (Vukovic et al. 1998). Homogeneous nucleation (precipitation directly from solution) will generally not occur except at very high metal concentrations, for example, greater than 10 parts per million (ppm). However, at low concentrations of the substituting cation (such as calcium) and in the presence of small amounts of phosphate and a seed crystal of apatite, heterogeneous nucleation occurs on the surface of the apatite seed crystal (Lower et al. 1998). The apatite itself serves as a small, but sufficient source of phosphate to solution and, thus, perpetuates the precipitation reaction. Over time, the precipitated metals are sequestered into the apatite crystal matrix.

The feasibility of Sr-90 sequestration by aqueous injection of Ca-citrate- $\mathrm{PO}_{4}$ has been demonstrated at the bench-scale at Sandia National Laboratories (Moore et al. 2004, 2006) and at Pacific Northwest National Laboratory using a series of batch tests that investigated in situ apatite precipitation and ${ }^{90} \mathrm{Sr}$ sorption/immobilization. Three experiments were conducted in which $\mathrm{Sr}-90$ was reacted with untreated and apatite-laden 100-N Area sediments and solid phase extractions were conducted to determine how the Sr-90 is bound on the surface (extractions: Amrhein et al. 1990; Sposito et al. 1982, 1983; Sparks 1996). It was hypothesized that $\mathrm{Sr}$ is "sorbed" to untreated sediment predominantly by ion exchange, and in contrast, apatite-laden sediments will (over time) more permanently sequester Sr. Two different apatiteladen sediment experiments were conducted: a) Sr-90 solution was added to the apatite-laden 100-N Area composite sediment, and b) apatite precipitate was added to the 100-N Area sediment from the 13-ft depth (which contains $80 \mathrm{pCi} / \mathrm{g} \mathrm{Sr}-90$ in contact with sediment for decades). Differences in $\mathrm{Sr}$ sequestration represent the influence of decades of Sr-90/sediment aging (if any for Sr-90 adsorbed for decades versus a day). For the untreated sediment, $86 \%$ of the Sr-90 could be extracted by ion exchange $\left(0.5 \mathrm{M} \mathrm{KNO}_{3}\right), 6 \%$ by a carbonate extraction $(0.05 \mathrm{M} \mathrm{EDTA})$, and about $6 \%$ by a mineral dissolution extraction $\left(4 \mathrm{M} \mathrm{HNO}_{3}\right.$ at $80^{\circ} \mathrm{C}$ for $24 \mathrm{~h}$, Table A.1). The remaining $5 \% \mathrm{Sr}-90$ was aqueous. Therefore, Sr-90 was retained on untreated 100-N Area sediments predominantly by ion exchange, as expected. In contrast, the Sr-90 was more difficult to remove from the apatite-laden sediments. In the sediment in which Sr-90 was added to apatite-laden sediment (Figure A.4, Table A.1), by 1 week, only $50 \%$ of the Sr- 90 could be extracted by ion exchange, $31 \%$ by the carbonate extraction, and $6 \%$ by the residual extraction. By 10 weeks, $42 \%$ of the Sr- 90 could be extracted by ion exchange, $44 \%$ by carbonate extraction, and $12 \%$ by the residual extraction. Therefore, about half the $\mathrm{Sr}-90$ mass is not bound by ion 
exchange after a week, and additional changes decreasing the ion exchangeable Sr-90 are occurring between 5 and 10 weeks. Extraction results for the Sr-90 field-contaminated sediment were similar, indicating little influence of aging. This mechanism (solid state ion exchange) of $\mathrm{Sr}$ substitution for $\mathrm{Ca}$ in the apatite structure has been previously studied at elevated temperature (Rendon-Angeles et al. 2000), but low temperature aqueous rates under Hanford groundwater conditions (i.e., $\mathrm{Ca} / \mathrm{Sr}$ of 220/1) have not.

\section{A.3 Apatite-Forming Solution Technology}

The method of emplacing apatite in subsurface sediments at the 100-N Area is to inject an aqueous solution containing a Ca-citrate complex and Na-phosphate. Citrate is needed to
Table A.1. Sr-90 Extraction from Sediments with Apatite

\begin{tabular}{|c|c|c|}
\hline $\begin{array}{l}\text { sediment } \\
\text { extraction }\end{array}$ & $\begin{array}{l}\text { no } \\
\text { treatment }\end{array}$ & $\begin{array}{l}--- \text { with apatite --- } \\
1 \text { month } 6 \text { months }\end{array}$ \\
\hline aqueous & 7.3 & $<0.2$ 市 \\
\hline exchangeable & 80.1 & 44.5市 \\
\hline 0.05M EDTA & 6.5 & $48.5 \mathrm{~S}_{\text {within }} 49.7 \mathrm{~A}$ \\
\hline 4M HNO3, $80 \mathrm{C}$ & 6.8 & 7.0 apatite $17.2^{\wedge}$ \\
\hline
\end{tabular}

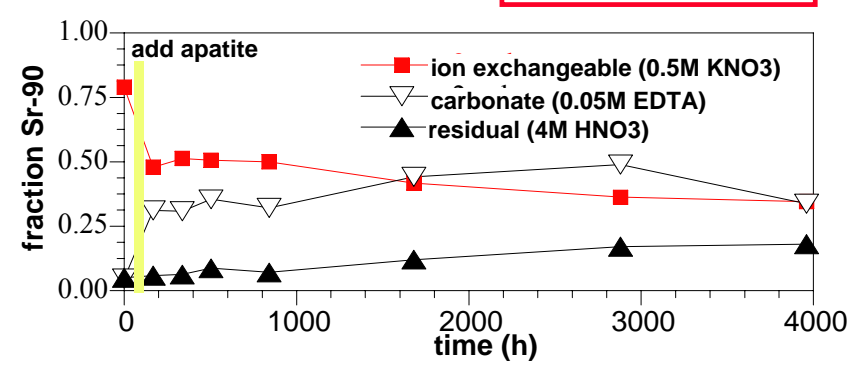

Figure A.4. Sr-90 Immobilization by Apatite Extraction Data keep $\mathrm{Ca}$ in solution long enough (days) to inject into the subsurface; a solution containing $\mathrm{Ca} 2+$ and phosphate only will rapidly form apatite (Andronescu et al. 2002; Elliot et al. 1973; Papargyris et al. 2002). Relatively slow biodegradation of the Ca-citrate complex (days) allows sufficient time for injection and transport of the reagents to the areas of the aquifer where treatment is required. As Ca-citrate is degraded (Van der Houwen et al. 2001; Misra 1996), the free Ca and phosphate combine to form amorphous apatite. The formation of amorphous apatite occurs within a week and crystalline apatite forms within a few weeks. Citrate biodegradation rates in Hanford 100-N Area sediments (watersaturated) at temperatures from $10^{\circ} \mathrm{C}$ to $21^{\circ} \mathrm{C}$ (aquifer temperature $15^{\circ} \mathrm{C}$ to $17^{\circ} \mathrm{C}$ ) over the range of citrate concentrations to be used $(10 \mathrm{mM}$ to $100 \mathrm{mM})$ have been determined experimentally (Table A.2) and simulated with a first-order model (Bailey et al. 1986; Brynhildsen and Rosswall 1997). In addition, the microbial biomass has been characterized with depth and position along the shoreline.

Table A.2. Ca-Citrate- $\mathrm{PO}_{4}$ Solution/Sediment Interaction with Citrate Biodegradation Rates

\begin{tabular}{|c|c|c|c|}
\hline Citrate $(\mathrm{mM})$ & $\begin{array}{c}\text { Biodeg rate, } 10^{\circ} \mathrm{C} \\
(1 / \mathrm{h})\end{array}$ & $\begin{array}{c}\text { Biodeg. rate, } 15^{\circ} \mathrm{C} \\
(1 / \mathrm{h})\end{array}$ & $\begin{array}{c}\text { Biodeg. Rate, } 21^{\circ} \mathrm{C} \\
(1 / \mathrm{h})\end{array}$ \\
\hline 10 & 0.0071 & 0.013 & 0.025 \\
\hline 50 & 0.0074 & 0.0036 & 0.013 \\
\hline 100 & 0.0024 & 0.0042 & 0.0075 \\
\hline
\end{tabular}

Multiple characterization techniques were employed (Figure A.5) to assess the crystal chemistry of the apatite formed by the microbial digestion of Ca-citrate in the Hanford 100-N Area sediment. High resolution transmission electron microscopy (HRTEM) and X-ray powder diffraction (XRD) were used to assess apatite crystallinity and to document the transformation from an amorphous calcium phosphate to nanocrystalline apatite. Energy dispersive (EDS) and Fourier transform-infrared (FT-IR) spectroscopy were used to analyze the chemical constituents. Blade-like crystals in an amorphous matrix are 

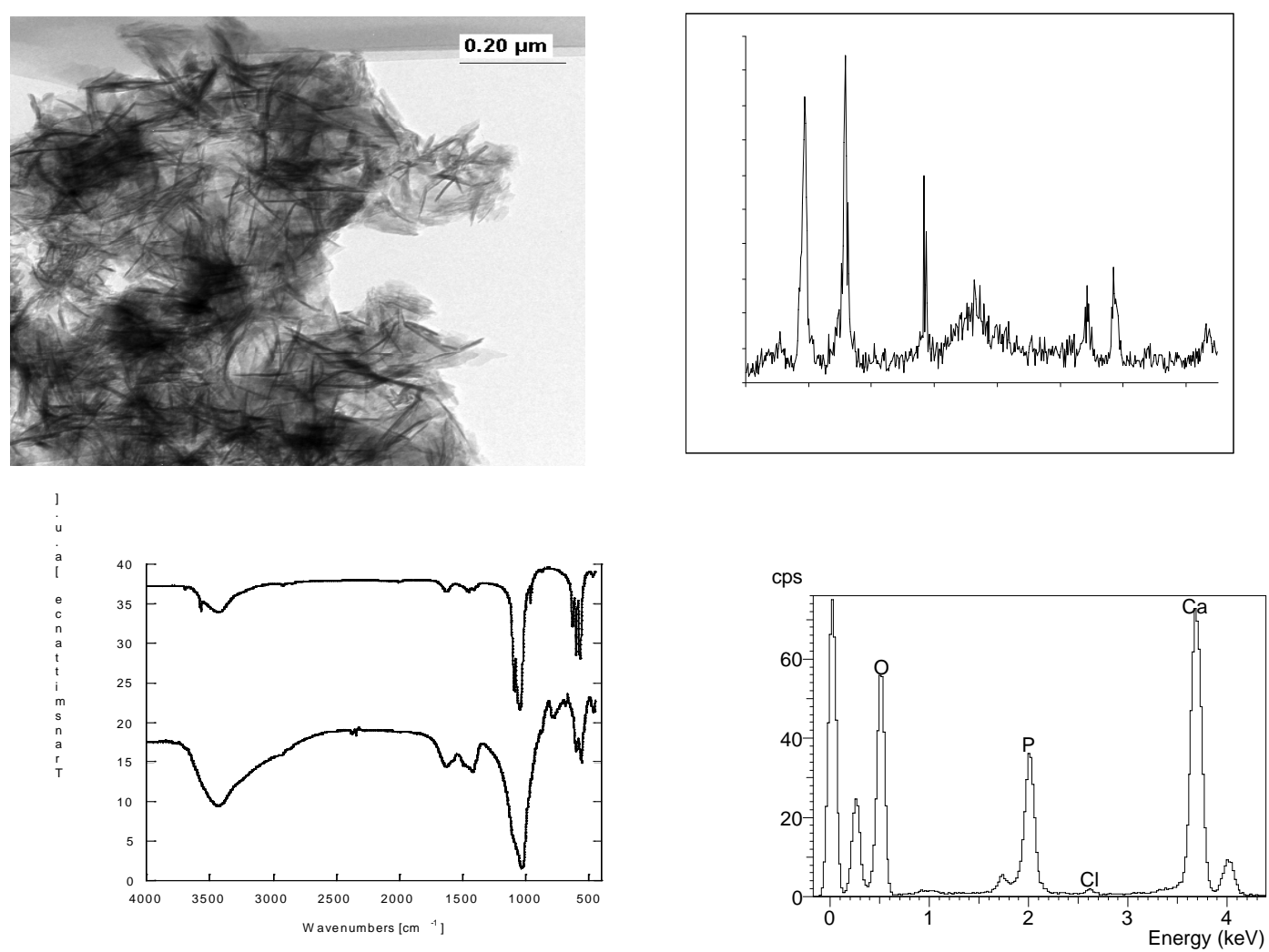

Figure A.5. Apatite Characterization by: (a) HRTEM, (b) XRD, (c) FT-IR, and (d) EDS of Nanocrystalline Apatite Formed in Hanford Sediment by Microbially Mitigated Ca-Citrate Degradation in the Presence of Aqueous Phosphorous

approximately $0.1 \mu \mathrm{m}$ in size (Figure A.5, upper left). This was consistent with the observed broad overlapping peaks in the XRD pattern at 2 microns of approximately $32^{\circ}$, a typical characteristic of poorly crystallized apatite (Figure A.5, upper right; Waychunas 1989; Nancollas 1970, 1974; Hughes et al. 2002). The remaining peaks in the XRD correspond to components of the sediment. FT-IR spectra are given for pure hydroxyapatite (top spectrum) produced by precipitation and heat treatment at $700^{\circ} \mathrm{C}$ and calcium phosphate precipitates in the Hanford 100 North Site sediment after one month (bottom spectrum). The lower resolution of the $\mathrm{PO}_{4}$-bands confirms the lower crystallinity of the sample, as observed by both HRTEM and XRD. The bands at $1455 \mathrm{~cm}^{-1}$ and $879 \mathrm{~cm}^{-1}$ indicate the presence of carbonate in the apatite structure. The TEM-EDS spectrum identifies calcium and phosphate as the major components with a stoichiometric apatite ratio of approximately $5: 3$.

\section{A.4 Need for Infiltration Strategy at River Shore}

The current plan to inject the Ca-citrate- $\mathrm{PO}_{4}$ solution separately into the Hanford formation and Ringold E Formation sediments. While there is a high degree of confidence that apatite precipitate will occur, the river hydrodynamics create a significant problem for the seasonal timing of the injection. Simulation of injections into the lower (less transmissive) Ringold E Formation at sustained low and high river stage show that the river stage does not move the Ca-citrate- $\mathrm{PO}_{4}$ injection plume a significant 
distance before apatite is expected to precipitate, so the time of year for injection into the Ringold E Formation is best at lower river stages (late fall) to get some apatite movement toward the river, but the timing is not critical.

In contrast, apatite-forming solution injection into the upper Hanford formation needs to be done during high river stage so that the formation is water saturated (i.e., late spring). In addition, because movement of the solution is desired toward the river, the most desirable injection river stage would be a high river stage (saturating the formation) followed by a moderate river stage, to get slow flow toward the river. Injection during low river stage would result in rapid movement of the injection solution into the river (days) before precipitation would occur. Therefore, river hydrodynamics have a potentially significant influence on the effectiveness of the emplacement of the solution by injection. There are only short periods throughout the year where the river stage conditions are optimal for injection.

Infiltration of the solution (proposed, described in the following sections) could be accomplished at a different river stage than injection, so an infiltration strategy extends the amount of time that apatite could be emplaced. Infiltration into the Hanford formation sediments would be optimal at periods of low river stage (leaving a greater thickness of unsaturated porous media), so could occur during summer/fall, or the second low stage of early spring. The formation of apatite during infiltration during these periods is less influenced by transmissivity in the formation and river stage, and more dependent on the rate of infiltration. Another potential benefit to infiltration is that cost of implementation may be much less than injection, as wells (a significant cost) do not need to be installed, although there is some cost associated with the infiltration method (i.e., trenches, drip emitters, etc).

\section{A.5 References}

Amrhein C and DL Suarez. 1990. "Procedure for Determining Sodium-Calcium Selectivity in Calcareous and Gypsiferous Soils.” Soil Sci. Soc, Am. J, 54:999-1007.

Andronescu E, E Stefan, E Dinu, and C Ghitulica. 2002. “Hydroxyapatite Synthesis.” Key Engineering Materials 206(2):1595-1598.

Arey JS, JC Seaman, and PM Bertsch. 1999. "Immobilization of Uranium in Contaminated Sediments by Hydroxyapatite Addition." Environ. Sci. Technol. 33(2):337-342.

Bailey JE and DF Ollis. 1986. Biochemical Engineering Fundamentals, Second Edition. McGraw-Hill, Inc., New York, p 246-250.

Bailliez S, A Nzihou, E Beche, and G Flamant. 2004. "Removal of Lead (Pb) by Hydroxyapatite Sorbent.” Process Safety Environ. Prot. 82(2)B:175-180.

Belousova E, W Griffin, S OReilly, and N Fisher. 2002. “Apatite as an Indicator Mineral for Mineral Exploration: Trace-Element Compositions and Their Relationship to Host Rock Type. J. Geochem. Exploration 76:45-69.

Brynhildsen, L and T. Rosswall. 1997. "Effects of Metals on the Microbial Mineralization of Organic Acids." Water Air Soil Poll. 94(1-2) p. 45-57. 
DOE. 2005. Strontium-90 Treatability Test Plan for 100-NR-2 Groundwater Operable Unit. DOE/RL-2005-96, Draft A, U.S. Department of Energy, Richland, Washington.

Elliot JC, PE Mackie, and RA Young. 1973. "Monoclinic Hydroxyapatite.” Science 180:1055-1057.

Fuller CC, JR Bargar, and JA Davis. 2003. "Molecular-Scale Characterization of Uranium Sorption by Bone apatite Materials for a Permeable Reactive Barrier Demonstration.” Environmental Science \& Technology 37(20):4642-4649.

Fuller CC, JR Bargar, JA Davis, and MJ Piana. 2002. "Mechanisms of Uranium Interactions with Hydroxyapatite: Implications for Groundwater Remediation." Environmental Science and Technology 36(2):158-165.

Heslop D, Y Bi, A Baig, M Otsuka, and W. Higuchi. 2005. "A Comparative Study of the Metastable Equilibrium Solubility Behavior of Carbonated Apatites Using pH and Solution Strontium as Independent Variables.” J. Coll. Interf. Sci 289:14-25.

Hughes JM and J Rakovan. 2002. "The Crystal Structure of Apatite, $\mathrm{Ca}_{5}\left(\mathrm{PO}_{4}\right)_{3}(\mathrm{~F}, \mathrm{OH}, \mathrm{Cl})$." In Phosphates: Geochemical, Geobiological and Materials Importance, Reviews in Mineralogy and Geochemistry, Vol 48, Mineralogical Society of America, Washington, D.C., p. 1-12.

Hughes JM, M Cameron, and KD Crowley. 1989. "Structural Variations in Natural F, OH and Cl Apatites." Amer Mineral 74:870-876.

ITRD. 2002. Hanford 100-N Area Remedial Options Evaluation Summary Report. Innovative Treatment and Remediation Demonstration Program, Sandia National Laboratory, Albuquerque, NM.

Jeanjean J, JC Rouchaud, L Tran, and M Fedoroff. 1995. "Sorption of Uranium and Other Heavy Metals on Hydroxyapatite.” J. Radioanal. Nucl. Chem. Lett. 201(6):529-539.

LeGeros RZ, G Quirolgico, and JP LeGeros. 1979. "Incorporation of Strontium in Apatite: Effect of pH.” J. Dental Research. 58:169.

LeGeros RZ. 1991. Calcium Phosphates in Oral Biology and Medicine. Basel, Switzerland, S. Karger.

Lower SK, PA Maurice, SJ Traina, and EH Carlson. 1998. “Aqueous Lead Sorption by Hydroxyapatite: Applications of Atomic Force Microscopy to Dissolution, Nucleation and Growth Studies. American Mineralogist 83: 147-158.

Mavropoulos E, AM Rossi, AM Costa, CAC Perez, JC Moreira, and M Saldanha. 2002. "Studies on the Mechanisms of Lead Immobilization by Hydroxyapatite.” Env. Sci. \& Technol 36(7):1625-1629.

Misra DN. 1996. "Interaction of Citric Acid with Hyrdoxyapatite: Surface Exchange of Ions and Precipitation of Calcium Citrate.” J. Dent. Res. 75(6):1418-1425.

Moore R, J Szecsody, M Truex, K Kelean, R Bontchev, and C Ainsworth. 2006. "Formation of Nanosize Apatite Crystals in Sediments for Contaminant and Stabilization of Contaminants." Nanoscale Technologies for Remediation, book chapter, F Burns (ed.), submitted. 
Moore, R.C., C. Sanchez, K. Holt, P. Zhang, H. Xu and G. Choppin. "Formation of Hydroxyapatite in Soils Using Calcium Citrate and Sodium Phosphate for Control of Strontium Migration." Radiochimica Acta 92.9-11 (2004): 719-723.

Moore RC, M Gasser, N Awwad, K Holt, F Salas, A Hasan, M Hasan, H Zhao, and C. Sanchez. 2005. "Sorption of Plutonium(VI) by Hydroxyapatite." J. Radioanaly. and Nuc. Chem. 263.1:97-101.

Moore RC, C Sanchez, K Holt, P Zhang, H Xu and G Choppin. 2004. "Formation of Hydroxyapatite in Soils Using Calcium Citrate and Sodium Phosphate for Control of Strontium Migration." Radiochimica Acta 92.9-11:719-723.

Moore RC, K Holt, H Zhao, A Hasan, N Awwad, M Gasser, and C Sanchez. 2003. "Sorption of Np(V) by Synthetic Hydroxyapatite.” Radiochim. Acta. 91:721-727.

Nancollas GH and MS Mohan. 1970. "The Growth of Hydroxyapatite Crystalls." Arch Oral Biol 15:731-745.

Nancollas GH and BB Tomazic. 1974. "Growth of Calcium Phosphate on Hydroxyapatite Crystalls, Effect of Supersaturation and ionic Medium.” J. Phy. Chem.79:2218-2225.

Papargyris AD, AI Botis, and SA Papargyri. 2002. "Synthetic Routes for Hydroxyapatite Powder Production.” Key Engineering Materials 206(2):83-86.

Rendon-Angeles J, K Yanagisowa, N Ishizawa, and S Oishi. 2000. "Effect of Metal Ions of Chloroapatites on the Topotaxial Replacement by Hydroxyapatite Under Hydrothermal Conditions." J. Solid State Chemistry 154:569-578.

Routson RC, G Barney, R Smith, C Delegard, and L Jensen. 1981. Fission Product Sorption Parameters for Hanford 200 Area Sediment Types. RHO-ST-35, Rockwell Hanford Operations, Richland, Washington.

Serne RJ and VL LeGore. 1996. Strontium-90 Adsorption-Desorption Properties and Sediment Characterization at the 100-N Area. PNL-10899, Pacific Northwest Laboratory, Richland, Washington.

Smiciklas I, A Onjia, J Markovic, and S Raicevic. 2005. "Comparison of Hydroxyapatite Sorption Properties Towards Lead, Zinc and Strontium Ions.” Mat. Sci. Forum 494:405-410.

Steefel C. 2004. "Evaluation of the Field-Scale Cation Exchange Capacity of Hanford Sediments." Water-Rock Interaction, E Wanty and P Seal (eds.), London, England, p. 999- 1002.

Sparks DL (ed.). 1996. "Methods of Soil Analysis, Part 3. Chemical Methods." Soil Science Society of America Book Series 5.

Spence RD and C Shi (eds). 2005. "Solidification and Stabilization of Hazardous, Radioactive and Mixed Wastes.” CRC Press, Boca Raton, Florida. 
Sposito G, L Lund, and A Chang. 1982. "Trace Metal Chemistry in Arid-Zone Field Soils Amended with Sewage Sludge: 1. Fractionation of $\mathrm{Ni}, \mathrm{Cu}, \mathrm{Zn}, \mathrm{Cd}$, and $\mathrm{Pb}$ in Solid Phases." Soil Sci Soc. Am J. 46:260-264.

Sposito G, C LeVesque, J LeClaire, and A Chang. 1983. "Trace Metal Chemistry in Arid-Zone Field Soils with Sewage Sludge: 3. Effect of Time on the Extraction of Trace Metals." Soil Sci Soc. Am J. 47:898-902.

Tofe AJ. 1998. Chemical Decontamination Using Natural, Artificial Bone. U.S. Patent 5,711,015.

Van der Houwen JAM and E Valsami-Jones. 2001. "Influence of Organic Ligands on the Precipitation of Calcium Phosphate at Neutral pH." Proceedings of the $11^{\text {th }}$ Annual V.M. Goldschmidt Conference.

Verbeek RM, HP Hauben, E Thun, and F. Verbeek. 1977. "Solubility and Solution Behavior of Strontium Hydroxyapatite.” Z. Phys. Chem (Wiesbaden) 108(2):203-215.

Vukovic Z, S Lazic, I Tutunovic, and S Raicevic. 1998. "On the Mechanism of Strontium Incorporation into Calcium Phosphates." J. Serbian Chem. Soc. 63(5):387-393.

Waychunas G. 1989. "Luminescence, X-Ray Emission and New Spectroscopies.” Rev Mineral 18:638-698.

Wright J. 1990. "Conodont Apatite: Structure and Geochemistry." In Biomineralization: Patterns, Processes and Evolutionary Trends, J Carter (ed.), p 445-459, Van Nostrand Reinhold, New York.

Wright J, K Rice, B Murphy, and J Conca. 2004. "PIMS Using Apatite II: How It Works to Remediate Soil and Water." In Sustainable Range Management, R Hinchee and B Alleman (eds.), Battelle Press, Columbus, Ohio. 


\section{Appendix B}

\section{Response to Summary Comments from Supplemental Columbia}

River Activities Peer Review 


\section{Appendix B}

\section{Response to Summary Comments from Supplemental Columbia River Activities Peer Review}

\section{B.1 Summary Evaluation}

Comment. The panel provided qualified support for the infiltration strategy, although had some technical issues (described in detail below).

Comment, second paragraph. Relative benefits of the proposed technology versus alternatives and variations in reagent chemistry should be provided.

Response. Some of the Sr-90 mitigation alternatives are described in the Treatability Test Plan for the Groundwater Injection (DOE 2005). Alternatives for treatment were evaluated and described in a 2001 document (Hanford 100N Area Remediation Options Evaluation Summary Report). Monitored natural attenuation (i.e., radioactive decay of Sr-90) will remove considerable Sr-90 mass from much of the plume, but not the portion near the river shore, which is entering the river. Soil flushing, clinoptilolite, sheet pile, cryogenic barrier were all evaluated and some attempted (soil flushing, sheet pile). In 2004, Fluor/CH2M HILL reevaluated alternative technologies and reiterated the conclusion of the 2001 ITRD report that phytoremediation and apatite (in some form) are the most promising. Evaluated for effectiveness, implementability, reduction of near-shore contamination, public acceptance, risk, and cost, several apatite technologies were considered acceptable: aqueous injection, air injection (solid apatite), hydrofracture, and hydrofracture grout curtain. Air injection of solid apatite was not viable due to the near surface need (i.e., insufficient overburden of sediment to force apatite laterally into formation). Hydrofracturing (i.e., GeoSierra) might work, although the use of apatite has not been attempted. This alternative was considered too expensive $(\$ 10 \mathrm{M}$ for a $300-\mathrm{ft}$ wall), and there was no evaluation as to the effectiveness of a very thin (i.e., 2-4 inch) apatite barrier on having sufficient residence time to sequester Sr-90 from groundwater. The grout curtain is similar, with some sections bentonite grount, and some sections apatite, although this actually creates an even higher flow problem through the apatite. The plan of digging a 40-ft deep trench at the Columbia River edge (river stage $\pm 8 \mathrm{ft}$ ) with Sr-90 laden-sediment and installing solid phase apatite was considered too risky and expensive. The alternative of minimal invasive injection of a solution that causes apatite precipitation was considered a good technology to emplace apatite, and was less costly. The polyphosphate injection method is also a good technology for emplacement, but due to budgetary considerations, was being developed under a separate project (for $\mathrm{U}$ remediation) as the Ca-citrate-phosphate injection technology was being developed for Sr-90 remediation. The development of the injection/infiltration method is not specific to the contaminant of interest, and scientists working on both of these projects do collaborate, so if one appears clearly more efficient, then the technology will be changed.

Variations in the Ca-citrate-phosphate chemistry. While this was not described in the proposal, there has been development work on the separate project of the solution composition. The original solution composition (Moore et al. 2004) has been modified slightly to incorporate a mixture of sodium and 
disodium phosphate so that the $\mathrm{pH}$ is 7.5 without modification (lowers the ionic strength by no base or acid additions). This solution composition will be used for injections in the 100N area in FY 2006:

$10 \mathrm{mM}$ trisodium citrate $[\mathrm{HOC}(\mathrm{COONa})(\mathrm{CH} 2 \mathrm{COONa}) 2 * 2 \mathrm{H} 2 \mathrm{O}] \mathrm{fw} 294.1 \mathrm{~g} / \mathrm{mol}$

$2.0 \mathrm{mM}$ disodium phosphate $\left[\mathrm{Na}_{2} \mathrm{HPO}_{4}\right]$, fw $141.96 \mathrm{~g} / \mathrm{mol}$

$0.4 \mathrm{mM}$ sodium phosphate $\left[\mathrm{NaH}_{2} \mathrm{PO}_{4}\right]$, fw $119.98 \mathrm{~g} / \mathrm{mol}$

$1.0 \mathrm{mM}$ ammonium nitrate $\left[\mathrm{NH}_{4} \mathrm{NO}_{3}\right]$, fw $80.04 \mathrm{~g} / \mathrm{mol}$

$4.0 \mathrm{mM}$ calcium chloride, $\left[\mathrm{CaCl}_{2} * 2 \mathrm{H} 2 \mathrm{O}\right]$, fw $147.02 \mathrm{~g} / \mathrm{mol}$

Three additional solution modifications are being tested at the laboratory stage. To further reduce the ionic strength ammonium dihydrogen phosphate could used. We tested this formula and there is little difference in the biodegradation rate (i.e., more $\mathrm{N}$ from ammonium), but only a very small difference in the total ionic strength. We are currently testing the use of ammonium hydrogen phosphate (dibasic), which would have a more significant decrease in the ionic strength. The last solution modification tested was using a combination of tricalcium citrate with trisodium citrate to lower the ionic strength and sodium injected. The tricalcium citrate is difficult to solubilize, requiring both sonication and heat, so likely not practical on an industrial scale. The ionic strength was $6 \%$ lower.

Comment, third paragraph. Panel recommends identifying a hydrologist, geologist, or engineer as substantive collaborator for this project.

Response. We agree that successful implementation of this technology requires a combination of disciplines (geochemistry, hydrology, and microbiology). Of the six investigators of this project, two are geochemists by training (John Fruchter, PI; Bob Moore), one chemist (Carolyn Burns), and three hydrologists (Jim Szecsody, Mark Rockhold, and Mart Oostrom). Jim Szecsody (PhD Hydrology, U of Arizona) has focused his career on chemical/microbial reactions and transport, so primarily experimental/modeling work at a batch, 1-D, and 2-D flow field scale. Mark Rockhold (PhD Engineering, Oregon State $U$ ) has focused his career on vadose zone flow processes (predominantly modeling, but $\mathrm{PhD}$ work was experimental/modeling microbial growth and transport). Mart Oostrom (PhD Soil Physics, Auburn U) has focused his career on vadose zone flow processes (water, multiple liquids, gas phases), predominantly experimental.

In addition to those scientists listed, Vince Vermeul and Mark Williams will be involved in the planning for infiltration experiments and interface with the field, as these scientists/engineers were involved in the 70-well in situ redox manipulation scaleup and are currently involved in the apatite injection scaleup. Two microbiologists are also involved, Mike Truex and Dave Culley.

\section{B.2 Technical Issues for Consideration}

Comment 1. Technical basis for proposed 300-year longevity calculation or endpoint decision.

Response. This information was not included in the proposal, but was added.

- Three hundred years of capacity is purely a function of the Sr-90 half-life (28.1 years), so 10+ halflives would decay $99.90 \%$ of the Sr-90. Whether Sr-90 is held in the apatite or is inland from the 
Columbia River and does not reach the river, only $10 \%$ will remain after 100 years and $<0.1 \%$ after 300 years.

- Basis for number of pore volumes of water passing through the barrier for 300 years: pv/15 m thick barrier x $0.3 \mathrm{~m} /$ day (average gw flow) x 365.25 day $/ \mathrm{yr}$ x $300 \mathrm{yr}=2191 \mathrm{pv}$

or roughly 2200 pore volumes of water traveling at $0.3 \mathrm{~m} /$ day $(1 \mathrm{ft} /$ day $)$ average groundwater flow rate will pass through a $15 \mathrm{~m}$ (45-ft) thick barrier in 300 years. We need to capture all of the $\mathrm{Sr}$ and $\mathrm{Sr}-90$ in these 3000 pore volumes. Ideally we are only interested in the Sr-90, but the solid phase substitution is the same for $\mathrm{Sr}$ and $\mathrm{Sr}-90$.

- $\mathrm{Sr}$ advection through the barrier in 300 years/2200 pore volumes: $0.2 \mathrm{mg} \mathrm{Sr} / \mathrm{L}$ (ave gw) or $2.0 \mathrm{E}-4$ $\mathrm{mg} \mathrm{Sr} / \mathrm{cm}^{3}$ x 2200 pore volumes $=0.44 \mathrm{mg} \mathrm{Sr} / \mathrm{cm}^{3}$ liquid

- Amount of apatite needed to sequester this amount of Sr: $0.44 \mathrm{mg} \mathrm{Sr} / \mathrm{cm}^{3}$ x 1/[44 g Sr/1004 g apatite $(11 \%$ substitution of $\mathrm{Sr}$ for $\mathrm{Ca})]=10.01 \mathrm{mg}$ apatite $/ \mathrm{cm}^{3}$ liquid

- Given the sediment field porosity $\left(0.20 \mathrm{~cm}^{3} / \mathrm{cm}^{3}\right)$ and dry bulk density $\left(1.78 \mathrm{~g} / \mathrm{cm}^{3}\right)$, the amount of apatite per gram of sediment is:

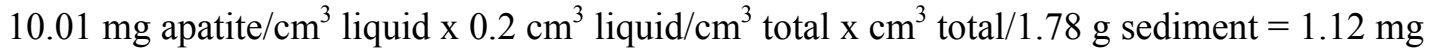
apatite/g sediment

- Phosphate solution (mol/L) required to achieve $1.2 \mathrm{mg}$ apatite/g sediment deposition mass: $10.01 \mathrm{mg}$ apatite $/ \mathrm{cm}^{3}$ liquid $\times 1000 \mathrm{~cm}^{3} / \mathrm{L} \mathrm{x} \mathrm{g/1000} \mathrm{mg} \mathrm{x} \mathrm{mol} \mathrm{apatite} / 1004 \mathrm{~g}$ apatite $\times 6 \mathrm{~mol} \mathrm{PO}_{4} / \mathrm{mol}$ apatite $=0.059 \mathrm{~mol} \mathrm{PO}_{4} /$ liter

Because phosphate solution concentrations of $0.04 \mathrm{~mol} / \mathrm{L}$ is soluble and has been used, it is estimated that two or more injections are required to achieve a deposition of $1.2 \mathrm{mg}$ apatite/g sediment

- Volume considerations of apatite in the pore space

unit cell of apatite: $\mathrm{a}=9.3 \mathrm{~A} \mathrm{x} \mathrm{c}=6.89 \mathrm{~A}$.

Assume cylinder $(\mathrm{a} / 2) 2 * 3.14 * \mathrm{c}=7.488 \times 10-21 \mathrm{~cm}^{3} /$ atom or $4509.6 \mathrm{~cm}^{3}$ per mol of apatite $1.7 \mathrm{mg}$ apatite $/ \mathrm{g} \mathrm{sed} * \mathrm{~mol} / 502 \mathrm{~g} * 1 / 1000 * 4509.6 \mathrm{~cm}^{3} / \mathrm{mol}=0.0153 \mathrm{~cm}^{3} / \mathrm{g}$ sed

Give the dry bulk density and porosity: $1.78 \mathrm{~g} / \mathrm{cm}^{3} / 0.2=8.9 \mathrm{~g} / \mathrm{cm}^{3}$ pore space

pore space occupied by apatite: $0.0153 \mathrm{~cm}^{3}$ ap $/ \mathrm{g}$ sed $\mathrm{x} 8.9 \mathrm{~g} \mathrm{sed} / \mathrm{cm}^{3}$ pore space $=0.136$

...or $1.7 \mathrm{mg}$ apatite/g sediment occupies $14 \%$ of the pore space (small, but likely some decrease in permeability).

- The above pore volume calculation (second bullet) is appropriate for groundwater flow (not vadose zone flow). Given the average annual precipitation at Hanford of $16 \mathrm{~cm} /$ year, the recharge rate (i.e., downward flux rate) is estimated at $0.1 \%$ to $2 \%$ (less with plant cover, more with coarse surface sediment and no plants), based on multiple different techniques and studies at Hanford. Therefore, downward migration of Sr-90 in the vadose zone is very slow, so technically the number of pore volumes migrating downward in the vadose zone is very small $(\sim 0.01$ pore volume/year $=1 \%$ recharge), so the mass of apatite needed to sequester Sr-90 for 300 years (first bullet) may be less. 
However, the Sr-90 contamination zone that is being remediated is near the Columbia River, and this zone may be at low water saturation or be seasonally part of the unconfined aquifer. As such, the "worst case" for vadose zone treatment is that $\mathrm{Sr}-90$ is migrating in groundwater (i.e., the vadose zone is watersaturated $100 \%$ of the time), so we are designing the same amount of precipitation in the vadose zone as in the saturated zone.

Comment 2. The proposal lacked a detailed description of the alternative selection process.

Response. See first response under the summary evaluation section.

Comment 3. Adequate research and experimental work has not been done to implement a full-scale project.

Response. We agree. In the current Fluor-funded 100-N Area remediation apatite injection project, we considered infiltration, but because we had never attempted precipitation of this solution under unsaturated conditions, nor designed an infiltration strategy for this solution, we could not implement. This proposal was written to scale up from bench scale processes to a 2-meter scale the infiltration technology. We did not include field work (i.e., small field test, for example) in this proposal because this work would likely be funded by Fluor. We are currently using a stepped process at the field scale for the 100-N Area apatite injection in wells: a) single well tracer injection, b) single well apatite solution injection, c) data analysis including coring to collect sediments for apatite analysis, and d) additional injections with same/modified injection strategy. In previous projects, we have successfully scaled up an aqueous injection of sodium dithionite by bench, 1-D column, 2-D wedge (radial) lab experiments at a 1-7 $\mathrm{m}$ scale, then small (single well) field scale, then multiple well field scale. Given that results of this proposal are successful, we would follow a similar scaleup at the field scale for infiltration.

Comment 3b. Consider conducting a field test.

Response. To conduct a successful field test, objectives must be clear. In a short time frame (weeks to months) we could clearly determine if a solution caused apatite precipitation. At the field scale $\left(15^{\circ}\right.$ to $17^{\circ} \mathrm{C}$ and low water content), we could not determine the long-term impact on Sr-90 immobilization (i.e., incorporation into the apatite structure), which would require transport of the Sr-90 in the vadose zone as well as time to incorporate into the structure. However, we can duplicate specific pieces (although only in idealized systems) of the process in the laboratory and determine if these processes occur. We have already conducted water-saturated injection experiments through Sr-90-laden sediments and have determined the relationship between the ionic strength and resulting Sr-90 mobility (caused by ion exchange), and within this proposal we are planning on duplicating some of these experiments at low water saturation (Task 2). The long term incorporation of Sr into apatite is Task 3 , in which we accelerate the incorporation rate by conducting experiments at $15^{\circ} \mathrm{C}, 35^{\circ} \mathrm{C}, 60^{\circ} \mathrm{C}$, and $80^{\circ} \mathrm{C}$, so we can clearly determine: a) the ultimate capacity that $\mathrm{Sr}$ can incorporate into the apatite structure and b) the Sr-90 incorporation rate.

Comment 4. Impacts of subsurface heterogeneities.

Response. While we can duplicate specific subsurface processes (i.e., flow through porous media, 1-D or 2-D), the impact of natural heterogeneities, we believe, is a very significant issue. In Task 5.1, we will test the injection strategy in a 2-D porous media system, so be able to track infiltration vertically and 
laterally (non-intrusive dual gamma system), and sample the solution. We hypothesize that a low concentration injection will behave similarly to water, but repeated high concentration injection may produce enough precipitation to alter the flow. Task 5.2 was to test the injection strategy in a heterogeneous porous media system. Due to the fluvial depositional environment of the Hanford formation, layers (not very laterally continuous) are significant. For vadose zone infiltration, a high-K layer causes an infiltration barrier (less capillary suction), so Task 5.2 will investigate this type of heterogeneity. The purpose of this subtask is to determine if a heterogeneity (high-K layer) is characterized, can an injection strategy be successful (such as initial high flow rate to exceed the capillary barrier, followed by a slower infiltration rate).

The first 2-D infiltration experiment will be infiltration into a homogenous sediment (Task 5.1), and the second infiltration experiment will be infiltration into layered sediment (high-K zone, Task 5.2). Additional heterogeneities will be tested through simulations (Task 4) that include laterally discontinuous layers (high-K, low-K) and random zones of hydraulic conductivity of different scales.

Comment 5. Diesel contamination.

Response. The diesel contamination (1966 spill) is somewhat upgradient (up on bluff) of the Sr-90 plume area, so most of the Sr-90 area will not be influenced and generally would affect the groundwater, but not the vadose zone near the river. However, well sampling downgradient of the diesel contaminated area shows indirect evidence of microbial activity (elevated ferrous iron). This is a zone of likely increased microbial activity, reduced iron, and possibly altering the Sr-90 mobility. The increase in ferrous iron may change the ion exchange reactions to some extent, so influence the $\mathrm{Sr} / \mathrm{Sr}-90$ mobility. The apatite solution injection (not infiltration) may be influenced (i.e., citrate would degrade more rapidly), and subsequently alter the injection rate. Diesel in the vadose zone would certainly affect the ability of infiltrating a solution. Residual diesel saturation will hinder the infiltration. As the extent of this diesel plume is investigated, we will investigate the infiltration strategy.

Comment 6. Apatite particle size.

Response. We do have some characterization of the apatite precipitate size (see Figure A.5), which are approximately 0.1 micron (from Moore et al. 2006). We have characterized Sr-90 sequestration in batch and 1-D columns with apatite in the sediments, so know that the precipitate remains immobile. We have not altered the precipitation method in an attempt to change the precipitate size, although this is an interesting (and useful) idea.

Comment 7. Consider mineral formation and how ${ }^{90} \mathrm{Sr}$ is incorporated.

Response. Task 3 is a series of long term batch studies designed to quantify both the rate of Sr-90 incorporation into apatite and the ultimate capacity of incorporation under various conditions. Under comment 1 (longevity), we assume 11\% Sr substitution for $\mathrm{Ca}$ in apatite, which is found naturally, although $100 \% \mathrm{Sr}$-apatites exist and $60 \% \mathrm{Sr}$ substitution for $\mathrm{Ca}$ has been shown experimentally. These Task 3 experiments will determine if we will achieve this capacity and the rate of incorporation. Both are vital, because if the incorporation rate is slower than the $\mathrm{Sr} / \mathrm{Sr}-90$ flux rate through the precipitate section, then Sr-90 will not be retained. While thermodynamically $\mathrm{Sr}$ should substitute for $\mathrm{Ca}$, and we have demonstrated this process in a year-long experiment, the sequence of experiments we are planning will determine the longevity of the barrier (i.e., how much apatite precipitate is necessary). Sr uptake by 
apatite (no sediment) in the first vial will be in DI water $(0.2 \mathrm{mg} / \mathrm{L} \mathrm{Sr}$, Na-perchlorate background electrolyte), and monitoring solution Sr-90 should show initial rapid (hours) uptake by ion exchange, then slow (months) additional uptake as $\mathrm{Sr}-90$ is incorporated into the apatite structure. Multiple vials will be used so that solid phase samples can be taken and sequential extractions be used to extract the Sr by dissolving the apatite. Experiments will be conducted at four temperatures from $15 \mathrm{C}$ to $80 \mathrm{C}$ in order to determine the activation energy (likely diffusion control) and predict the Sr uptake rate at different temperature. From this "baseline" experiment, additional vials will be conducted:

- influence of Ca: 2 vials, apatite only, same solution but with 20:1, and 220:1 Ca:Sr, does the presence of Ca slow the Sr uptake rate

- influence of trace metals: 5 vials, apatite only, but groundwater (containing 220:1 Ca:Sr, and other trace metals). Does the presence of other metals slow the Sr uptake rate. Solid phase analysis of some of these.

- influence of sediment: groundwater + apatite + sediment (sufficient for 10x sorption on sediment compared with apatite). Hypothesize that the sediment slows uptake by apatite but not ultimate capacity

- Sr uptake rate and 500 pore volume and 3000 pore volume equivalence of Sr. Use groundwater plus additional $\mathrm{Sr}$ and $\mathrm{Ca}$ to increase the Sr uptake mass. Hypothesize that as $\mathrm{Sr}$ (5\% for example) is substituted in the apatite structure, the additional uptake rate may be slower, as diffusion further into the structure is slower. These experiments may also be initiated with some $\mathrm{Sr}$ already in the Caapatite.

Comment 8. Citrate biodegradation rate.

Response. We agree that we need to understand the citrate biodegradation rate under varied conditions in the vadose zone. The apatite formation rate is rate limited by the citrate biodegradation rate (Task 1). We have considerable data in water-saturated systems at different citrate concentration $(10 \mathrm{mM}, 50 \mathrm{mM}$, $100 \mathrm{mM})$ and temperature $\left(10^{\circ} \mathrm{C}, 15^{\circ} \mathrm{C}, 22^{\circ} \mathrm{C}\right)$ in Hanford sediments that show there is a $1.8 \mathrm{x}$ increase/ $10^{\circ} \mathrm{C}$ increase, and $3 \mathrm{x}$ increase $(10$ to $100 \mathrm{mM})$. In this proposed work, Task 1.1 describes determining the citrate biodegradation rate at different water saturation. We will also conduct some experiments at different microbial biomass concentrations to determine citrate biodegradation rates (Task 1.3). We have field data that shows that the microbial population in the water-saturated zone varies about 2 orders of magnitude and in the vadose zone is generally higher, but varies 4 orders of magnitude. An order of magnitude increase in biomass does not equate to the same increase in biodegradation rate, but will result in a more rapid increase as exponential growth will occur sooner.

Comment 9. Stakeholder concern on leaving Sr-90 in place.

Response. We have had three public workshops that describe the proposed apatite technology (by injection) and list leaving Sr-90 in place (until radioactive decay) as a weakness, along with requires wells for installation (injection technology) - some disturbance. We have gotten some comments about this issue. Our response is that $\mathrm{Sr}-90$ is being decayed $3.6 \%$ per year (50\% remaining after 30 years, $10 \%$ remaining after 100 years, $<0.1 \%$ after 300 years) and if immobilized (in the aquifer or vadose zone) causes no adverse health impacts. In contrast, washed out into the river (or on river shore sediments), it is 
part of the food chain (demonstrated). Second, there are limitations as to the technology available. Sr-90 (Sr) does not undergo redox, so can be adsorbed (but this is temporary), be incorporated into apatite or other precipitate (permanent, dependent on solubility), is not effectively remediated by water pumping (due to proximity to the river and high $\mathrm{K}_{\mathrm{d}}(\mathrm{Rf}$ of $\sim 100)$ ). It would be possible to mobilize about $90 \%$ of the Sr-90 by a high $(1 \mathrm{M})$ salt injection, as we have conducted in laboratory experiments, but again the plume would not be controllable at the river shore, so this would likely result in a large increase in Sr-90 release to the river for years (although the long term problem would be smaller).

Comment 10. Nutrient loading and microbial increase.

Response. The details of the Ca-citrate-phosphate injection chemistry are described at the bottom of the first page of the review comments. We do inject (infiltrate) N, P, and an organic acid (citrate) and are expecting microbial growth. We have conducted considerable number of microbial growth (citrate biodegradation) experiments under various conditions (see comment 8 ) that will cover the range of our expected injections (10 $\mathrm{mM}$ citrate initial injection, subsequent injections are $70 \mathrm{mM}$ citrate). We have not, however, conducted multiple sequential injections over several months, which, as the reviewers suggest, could result in considerable microbial increase (clogging). The citrate biodegradation rates we observe are generally days, so our injections of 8-12 h (planned) will generally occur with little biodegradation, so we expect little bioclogging during well injection. We have, in fact, conducted a 20 - $\mathrm{ft}$ long 1-D column injection for $24 \mathrm{~h}$ and did not observe biofouling (generally observed nearly unretarded $\mathrm{Ca}$ and citrate breakthrough, some lag in phosphate breakthrough).

For the purpose of this proposed work on vadose zone infiltration, we expect that infiltration rates (water flux) rates will be slower than injection rates, so biofouling may be more of an issue than for well injection. This information was added to the proposal, and will be considered during the 1-D (Task 2) and 2-D (Task 5) infiltration experiments.

\section{B.3 Implementation Strategy}

Comment 11. Consider limited field tests.

Response. See comment 3, we agree that small field scale experiments are needed before implementation, but collaboration with Fluor on the current apatite injection study we are conducting small single-well injection experiment before implementation. We therefore expect that the small fieldscale studies would be conducted as part of Fluor-funded implementation, assuming results of this study are successful.

Comment 12. Revise schedule to met the 2008 TPA

Response: $x$

Comment 13. Using current data from well injections.

Response: Although this was not stated, we are planning on using laboratory and field data collected in saturated systems to apply to the vadose zone application. We considered infiltration on the injection project (Fluor funded), but since did not have any data on the biodegradation rate under unsaturated 
conditions, nor the complexities as precipitation alters flow both vertically and laterally, hydrologically, we believe that well injection is more straightforward (and as a consequence being implemented first).

\section{B.4 Proposed Performance Metrics}

Comment 14. Metrics are inadequate

Response: The following metrics were added to the proposal:

Task 1. Go/no-go decision on citrate biodegradation occurs at low water saturation conditions that will be used during infiltration $(50-100 \%$ saturation) $($ no $=$ stop work, $6 / 07)$

Task 2. Go/no-go decision: apatite will form during 1-D infiltration in $100 \mathrm{~N}$ sediments that is relatively uniform (no $=$ stop work, $8 / 07$ )

Task 3. Go/no-go decision: $\mathrm{Sr}$ is uptaken at a rate sufficiently rapid to exceed the Sr-90 average flux rate in water-saturated sediments $(9 / 07$, no $=$ stop work $)$

Task 3. Go/no go decision on implementation: the Sr capacity is $<1 \%$ in apatite (would be difficult to inject enough apatite to sequester Sr-90 for 300 years as the amount of apatite would fill most of the pore space $(6 / 08)$

Task 5. Go/no go decision on implementation: A 2-D infiltration experiment can be conducted and a relatively uniform (vertically and laterally) apatite precipitation distribution obtained (no = no go, 12/07).

Comment 15. Monitoring program

Response. A field-scale monitoring program is planned for the apatite injection technology, and if the results of this proposal are successful, field infiltration (Fluor funded) will include a monitoring program. This will involve drilling to obtain cores with leaching studies: a) presence of apatite limits Sr-90 release from sediments, and b) apatite is present over a wide spatial area. Groundwater analysis or water extraction from vadose zone sediments will also be used to show Sr-90 release influence by the presence of apatite.

\section{B.5 References}

DOE. 2005. Strontium-90 Treatability Test Plan for 100-NR-2 Groundwater Operable Unit. DOE/RL-2005-96, Draft A, U.S. Department of Energy, Richland, Washington.

Moore RC, C Sanchez, K Holt, P Zhang, H Xu and G Choppin. 2004. "Formation of Hydroxyapatite in Soils Using Calcium Citrate and Sodium Phosphate for Control of Strontium Migration." Radiochimica Acta 92.9-11:719-723.

Moore RC, M Gasser, N Awwad, K Holt, F Salas, A Hasan, M Hasan, H Zhao, and C. Sanchez. 2005. "Sorption of Plutonium(VI) by Hydroxyapatite." J. Radioanaly. and Nuc. Chem. 263.1:97-101. 